\title{
Effect of flue gas composition on deposit induced high temperature corrosion under laboratory conditions mimicking biomass firing. Part I: Exposures in oxidizing and chlorinating atmospheres
}

Okoro, Sunday Chukwudi; Kiamehr, Saeed; Montgomery, Melanie; Jappe Frandsen, Flemming; Pantleon, Karen

Published in:

Materials and Corrosion

Link to article, DOI:

10.1002/maco.201609173

Publication date:

2017

Document Version

Peer reviewed version

Link back to DTU Orbit

Citation (APA):

Okoro, S. C., Kiamehr, S., Montgomery, M., Jappe Frandsen, F., \& Pantleon, K. (2017). Effect of flue gas composition on deposit induced high temperature corrosion under laboratory conditions mimicking biomass firing. Part I: Exposures in oxidizing and chlorinating atmospheres. Materials and Corrosion, 68(15), 499-514 . https://doi.org/10.1002/maco.201609173

\section{General rights}

Copyright and moral rights for the publications made accessible in the public portal are retained by the authors and/or other copyright owners and it is a condition of accessing publications that users recognise and abide by the legal requirements associated with these rights.

- Users may download and print one copy of any publication from the public portal for the purpose of private study or research.

- You may not further distribute the material or use it for any profit-making activity or commercial gain

- You may freely distribute the URL identifying the publication in the public portal 


\title{
Effect of flue gas composition on deposit induced high temperature corrosion under laboratory conditions mimicking biomass firing. Part I: Exposures in oxidizing and chlorinating atmospheres
}

Sunday Chukwudi Okoro ${ }^{\mathrm{a},{ }^{*}}$, Saeed Kiamehr ${ }^{\mathrm{a}}$, Melanie Montgomery ${ }^{\mathrm{a}}$, Flemming Jappe Frandsen ${ }^{\mathrm{b}}$, Karen Pantleon ${ }^{\text {a }}$

${ }^{a}$ Department of Mechanical Engineering, Technical University of Denmark (DTU), 2800 Kongens Lyngby, Denmark.

${ }^{\mathrm{b}}$ CHEC Research Centre, Department of Chemical and Biochemical Engineering, DTU, 2800 Kongens Lyngby, Denmark.

* Phone: +45 50185680, Fax: +45 45936213, Email: sunoko@mek.dtu.dk, okorochukwudi@ymail.com

\begin{abstract}
In biomass fired power plants, deposition of alkali chlorides on superheaters, as well as the presence of corrosive flue gas species, give rise to fast corrosion of superheaters. In order to shed light on the corrosion mechanism under this complex condition, the influence of flue gas composition on high temperature corrosion of an austenitic superheater material under laboratory conditions mimicking biomass firing was investigated. Isothermal high temperature exposures at $560{ }^{\circ} \mathrm{C}$ for $72 \mathrm{~h}$ with deposit (KCl)-coated and deposit-free austenitic stainless steel (TP 347H FG) samples was conducted. Exposures were conducted under both oxidizing and oxidizing-chlorinating atmospheres, and the resulting corrosion products were comprehensively studied with Scanning Electron Microscopy (SEM), Energy Dispersive X-ray Spectroscopy (EDS) and X-ray Diffraction (XRD) techniques. The results show that deposit-free samples suffer grain boundary attack only in an oxidizing-chlorinating atmosphere, otherwise corrosion results in formation of a duplex oxide. Corrosion attack on depositcoated samples was higher than on deposit-free samples irrespective of the gaseous atmosphere. Specifically, severe volatilization of alloying elements occurred on deposit-coated samples under oxidizing-chlorinating atmosphere due to enhanced impact of $\mathrm{KCl}$ and $\mathrm{HCl}$.
\end{abstract}

Keywords: High temperature corrosion, Biomass, Stainless steel, SEM, XRD, Oxidation, Chlorination, Metal chlorides.

\section{Introduction}

High temperature corrosion of superheater tubes limits the efficiency of biomass fired power plants due to restriction of the outlet steam temperatures to a maximum of $540{ }^{\circ} \mathrm{C}$ during combustion of herbaceous biomass, like straw [1,2]. The corrosion problems arise from release of K-, S-, and Clspecies during combustion of biomass-based fuels [3-6], leading to formation of KCl-rich deposits 
(in the case of straw) along superheater tubes. This challenge has prompted investigations to reveal the mechanisms behind the corrosion attack. Studies have been approached either from a full-scale perspective of tubes exposed in the power plants, or from laboratory scaled exposures simulating the conditions observed in superheater sections of power plants.

Full-scale corrosion studies [2,7-12] often involve the use of either air or water cooled probes, test superheaters or sections welded into the existing superheater, in order to compare the performance of different materials. These studies provide information on the nature of corrosive deposits formed on the samples, allowing the deposit chemical composition to be correlated with the observed corrosion attack. From such studies, a Chlorine-induced attack originating from the deposit has been suggested to be responsible for the high-temperature corrosion rates observed [7]. In some studies [13], sulphidation has been identified when co-firing biomass with a fossil fuel. Although realistic information on the rate of corrosion attack are provided by full-scale corrosion studies, the complex fluctuating operating conditions (temperature, fuel type, boiler load etc.) in power plants limit systematic study of the corrosion mechanisms to a certain degree. Also, the very complex morphology of corrosion products resulting from such full-scale studies, in addition to the continuous shedding of deposits/corrosion products, does not straightforwardly allow the use of advanced characterization techniques which could help understand the underlying corrosion mechanisms.

On the other hand, laboratory scale studies [14-19] are usually dedicated to investigate specific parameters influencing corrosion. Results from such studies have highlighted the obscured role of $\mathrm{K}$ (in $\mathrm{KCl}$ deposits) in the early stages of the corrosion attack for high alloyed stainless steels [18]. The corrosivity of other species (for example, $\mathrm{NaCl}, \mathrm{CaCl}_{2}, \mathrm{~K}_{2} \mathrm{CO}_{3}$, etc.) has also been extensively investigated [20-23] in order to validate the role of the alkali metal in the corrosion attack. However, most laboratory scale studies oversimplify the corrosive atmospheres and consider single influences instead of the synergetic effects existing under real plant conditions. As a result, conclusions from these studies are not fully applicable to the complex situations in real power plants [17] since they do not take into account the simultaneous influence of parameters such as the flue gas and deposit composition including possible variations of these.

The influence of flue gas composition on the corrosion of superheater materials has been considered in some laboratory investigations [24-36]. Some of these studies were carried out on samples without a deposit [25-29,31], with high concentrations of the investigated flue gas species [35,37], or at temperatures above the actual superheater steam temperatures during biomass (straw)-firing $[32,36,38]$. To gain improved understanding of the corrosion mechanisms relevant to biomass-firing conditions, systematic laboratory scaled studies under conditions reasonably mimicking biomass firing are thus required. Such studies will help to bridge the gap between results from full-scale high temperature corrosion studies and those from simplified laboratory scale studies where fundamental understanding of the corrosion mechanisms has been established.

In the present work, the influence of flue gas composition on the high temperature corrosion of a superheater material (austenitic stainless steel, TP 347H FG) was systematically investigated under conditions similar to actual biomass firing. Corrosion exposures were carried out in a dedicated 
furnace, which allows mimicking biomass firing conditions in the laboratory. The flue gas concentrations corresponds to the highest concentration measured in a power plant firing biomass [11,39]. The investigation addressed both the effect of the flue gas, and its interaction with the deposit during the corrosion attack. To this end, some samples were coated with $\mathrm{KCl}$ before the corrosion exposure. Material characterization was carried out by both cross-sectional and plan-view 'top-down' depth-resolved analysis of the corrosion products. In the first part of this study (Part I, present paper), results from corrosion exposures of both deposit-coated and deposit-free samples to oxidizing and oxidizing-chlorinating gas mixtures are reported. In the accompanying paper (Part II, same journal volume) [40], results from exposure of deposit-coated and deposit-free samples to sulphidizing gas mixtures (with and without $\mathrm{HCl}$ ) are presented and discussed in detail.

\section{Experimental}

\subsection{High temperature corrosion exposure}

A tube of fine grained austenitic stainless steel TP 347H FG, commonly applied as superheaters in biomass-fired power plants, has been used for the investigation. The following chemical composition of the superheater tube was obtained by energy dispersive spectroscopy (EDS): $18.1 \mathrm{wt} \% \mathrm{Cr}, 10.3$ wt\% Ni, 2.0 wt\% Mn, 0.5 wt\% Nb, 0.4 wt\% Si with Fe as balance. Using Fusion thermal conductivity unit LECO CS230, a carbon content of $0.057 \mathrm{wt} \%$ has been identified for this material [41]. From the tube, rings with a width of $10 \mathrm{~mm}$ (longitudinal direction of the tube) were cut and further segmented such that arc-shaped samples of length $14.6 \mathrm{~mm}$ were obtained. The wall thickness of the tube, thus the height of the samples, was $7.4 \mathrm{~mm}$. The tube segments were ultrasonically degreased in acetone, cleaned in ethanol and dried. The tube segments were used in the as received condition with no form of surface preparation. Some of the samples were coated with $\mathrm{KCl}$, while other samples remained without any $\mathrm{KCl}$ on the surface. For coating the samples with a $\mathrm{KCl}$ deposit, crushed $\mathrm{KCl}$ with a particle size of [32 - $63 \mu \mathrm{m}$ ] (Sigma $\geq 99 \%$ ) was mixed with 2 - propanol and the resulting slurry was applied on the sample surface to give a final deposit thickness of $1 \mathrm{~mm}$. By using deposit slurries to coat the samples, a good and uniform contact between the deposit and the alloy surface is established after evaporation of the volatile solvent. In the power plant, the deposit forms on the convex (fireside) of the superheater tube, however in the lab-scale exposure the concave surface was $\mathrm{KCl}$ coated to ensure consistent contact between the deposit and sample throughout the exposure.

A dedicated corrosion test rig was employed for the high temperature corrosion exposures (Figure 1). The rig consists of a gas inlet/mixing unit which employed gas cylinders of specific composition and concentrations, an electrically heated furnace and a gas clean-up unit. The desired gas composition was obtained by controlling the flow rate of each gas component using mass flow controllers to result in either (a) an oxidizing or (b) an oxidizing-chlorinating gas mixture. The oxidizing gas consisting of 6 vol\% $\mathrm{O}_{2}$ and 12 vol\% $\mathrm{CO}_{2}$ was saturated with $13.4 \mathrm{vol} \% \mathrm{H}_{2} \mathrm{O}$ vapour by passing the gas mixture through a thermally regulated water bath maintained at $52{ }^{\circ} \mathrm{C}$. For some exposures, this humid gas mixture was also mixed with $400 \mathrm{ppmv} \mathrm{HCl}$ to give an oxidizing-chlorinating gas. For both mixtures, the gas mix was fed through a preheated gas channel into the furnace and $\mathrm{N}_{2}$ was employed as a carrier gas. 


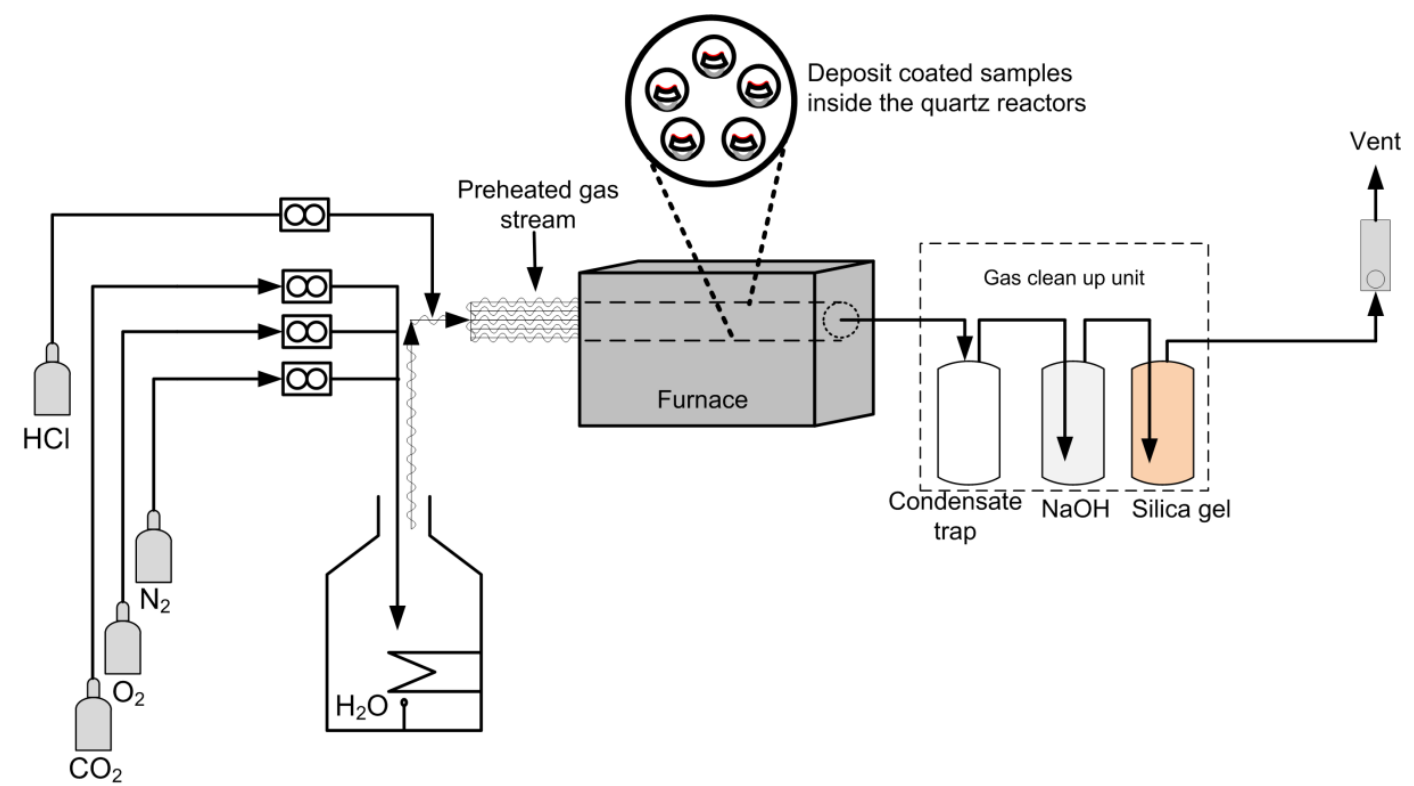

Figure 1. Schematic representation of the corrosion test rig used for high-temperature exposures.

Samples were placed in quartz reactors in the horizontal furnace with a minimum separation distance of $50 \mathrm{~mm}$, in order to minimize gas shielding effects. Both deposit-coated and deposit-free samples were exposed to each of the gas mixtures. Table 1 summarizes the experimental conditions applied in the present study. High temperature corrosion exposures were carried out isothermally at $560{ }^{\circ} \mathrm{C}$ for $72 \mathrm{~h}$. The test temperature was chosen to mimic the superheater outer surface metal temperature of biomass-fired plants operating at a steam temperature of $540{ }^{\circ} \mathrm{C}[2]$. After each exposure, the samples were cooled inside the reactors under a flow of $\mathrm{N}_{2}$.

Table 1. Summary of the experimental conditions investigated.

\begin{tabular}{llll}
\hline Experiment & $\begin{array}{l}\text { Deposit } \\
\text { coated? }\end{array}$ & Gas composition & \\
\hline Ia & Yes & Oxidizing gas: & $\mathrm{O}_{2}-6$ vol \% (dry), $\mathrm{CO}_{2}-12$ vol \% (dry), \\
Ib & No & & $\mathrm{N}_{2}-82$ vol \% (dry), $\mathrm{H}_{2} \mathrm{O}-13.4$ vol \% \\
\hline IIa & Yes & Oxidizing- & $\mathrm{HCl}-400 \mathrm{ppmv}\left(\right.$ dry), $\mathrm{O}_{2}-6$ vol \% (dry), \\
IIb & No & $\begin{array}{l}\text { chlorinating } \\
\text { gas: }\end{array}$ & $\mathrm{CO}_{2}-12 \mathrm{vol} \%$ (dry), $\mathrm{N}_{2}-82$ vol \% (dry), \\
& & $\mathrm{H}_{2} \mathrm{O}-13.4 \mathrm{vol} \%$ \\
\hline
\end{tabular}

2.2 Characterization of corrosion products

A combination of two methodologies for comprehensive characterization of the corrosion products were applied: (i) characterization of cross-sections and (ii) a plan view 'top-down' method involving stepwise mechanical removal of the corrosion product layers [42]. In both cases, complementary 
methods of materials characterization including microscopic, spectroscopic and diffraction techniques were used.

For cross-sectional investigations, a two-stage mounting procedure was employed for metallographic preparation. To retain the morphology of the corrosion products and the deposit, samples were mounted in epoxy under vacuum after exposure. The mounted samples were then sectioned under dry conditions in order to access the cross sections. In the second stage mounting, the sectioned samples were mounted in epoxy under vacuum with the exposed cross-section facing downwards. Afterwards the mounted samples were prepared according to standard metallographic techniques down to $1 \mu \mathrm{m}$ polishing using a diamond suspension. Due to the solubility of some of the corrosion products in water, absolute ethanol (VWR Chemicals, $99.9 \%$ ) was utilized as a lubricant in the metallographic preparation process, and samples did not get in contact with water.

The plan view 'top-down' characterization approach was employed to supplement results from crosssectional investigations. This reveals more detailed information on the corrosion products as some morphological features are obscured during the metallographic preparation process [42]. Plan view investigations on deposit coated samples started directly on the exposed deposits at the gas-deposit interface and proceeded with successive characterization of newly revealed surfaces after stepwise mechanical removal of the corrosion products using a scalpel or SiC paper. As a huge amount of results are revealed from this characterization method, selected results are presented here to supplement the cross section analysis.

Comprehensive characterization of the corrosion products was achieved by the complementary use of scanning electron microscopy (SEM) imaging, energy dispersive X-ray spectroscopy (EDS) and X-ray diffraction (XRD). Microstructure analysis with SEM (Inspect S, FEI) with an acceleration voltage of $15 \mathrm{keV}$ was employed for both cross-sectional and plan view investigations; surfaces were coated with carbon prior to microscopic characterization on cross sections. Micrographs were recorded using the backscatter electron detector (BSE). EDS (Oxford instruments) coupled to the SEM was used for elemental analysis of the corrosion products using an acceleration voltage of 15 $\mathrm{keV}$. Because of the heterogeneous morphology of the corrosion products, EDS results less than 1 wt\% were not considered from plan view investigations.

Qualitative phase identification of corrosion products was conducted by XRD. The diffractometer (Bruker AXS, D8 Discover) was equipped with a $\mathrm{Cr}-\mathrm{K} \alpha$ radiation source, and measurements were carried out in the grazing incidence mode (GI-XRD) with a fixed incidence angle $(\gamma)$ of $2^{\circ}$. Measurements were carried out on the original surfaces and after stepwise removal of the corrosion products, where the thickness of the removed layers was larger than the X-ray penetration depth. For XRD measurements on deposit-free samples, $\gamma=5^{\circ}$ was used, in order to cover a larger depth since no further corrosion product removal was carried out for these samples. Due to the curved geometry of the samples, the incident radiation was converged into a point focused beam using a polycap optic system and samples were placed such that the incident beam was not shielded by the sample curvature. 
Thermodynamic calculations were performed with the commercially available FactSage software $[43,44]$ to support the experimental results. Equilibrium calculations were performed using the Fact 53, FT Misc and FT pulp databases. The calculations were based on minimizing the Gibbs free energy of the system considered.

\section{Results}

\section{1 \\ Deposit (KCl) coated samples exposed to an oxidizing gas mixture (Experiment Ia)}

Figure 2 shows the cross section of samples coated with $\mathrm{KCl}$, after exposure to an oxidizing gas mixture; the two micrographs are representative of the corrosion morphologies observed. A compact double layered corrosion product was formed on some locations (Figure 2a). The outer layer (layer 1) of the corrosion product is observed to contain porosities. On some locations on the cross section (Figure 2b), very large voids are present above layer 1. Variations in contrast, observed in the lower layer of corrosion product (layer 2) suggest a difference in chemical composition within this layer. Below layer 2, corrosion attack proceeds into the bulk alloy preferentially through the grain boundaries.

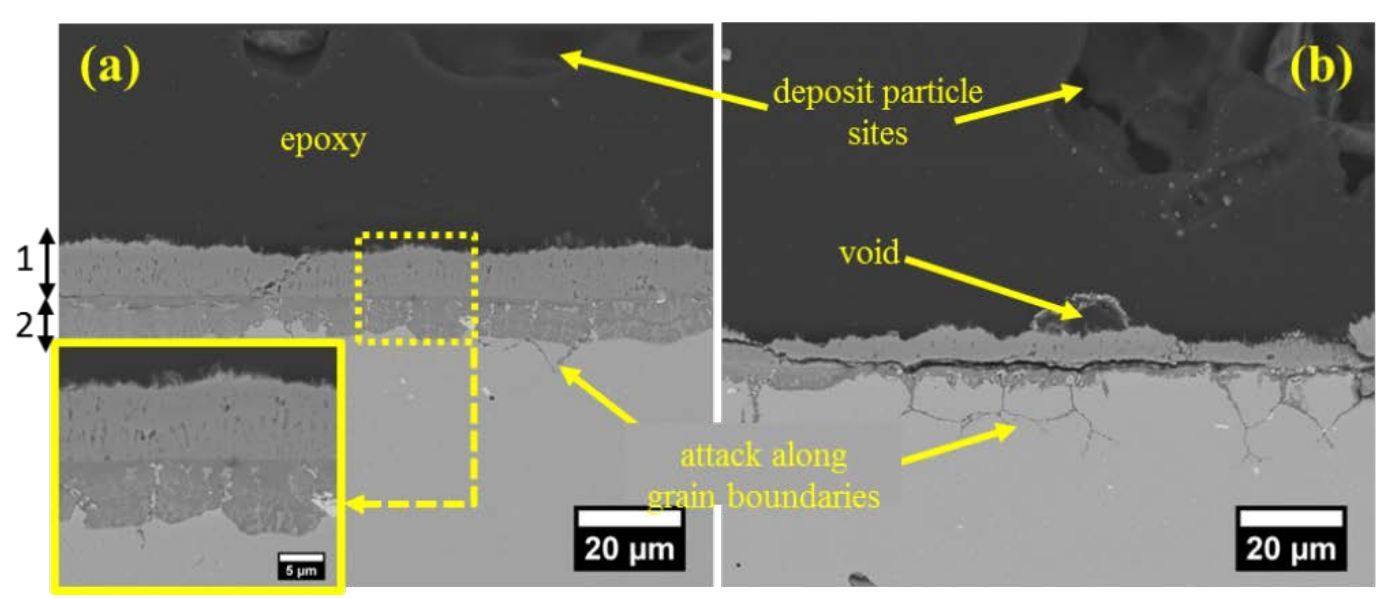

Figure 2. Micrographs showing cross-sections of deposit-coated samples exposed to an oxidizing gas mixture (i.e. experimental condition Ia). (a) Regions with lesser porosity in the corrosion product and (b) regions containing large voids and severe grain boundary attack. Double-headed arrows 1 and 2 indicate the different layers of corrosion product.

Elemental compositions of the corrosion product layers are revealed by the EDS maps shown in Figure 3. From these, it can be seen that Fe and $\mathrm{O}$ are the predominant elements in layer 1, whereas layer 2 of the corrosion product is enriched in $\mathrm{Cr}, \mathrm{Ni}$ and $\mathrm{O}$. From the $\mathrm{Ni}$ and $\mathrm{O}$ maps (Figure 3a), it is observed that in some points, Ni is not associated with O. Further, the Ni maps reveal that this element is mostly enriched at the lower regions of layer 2, and separates this layer from the bulk alloy. Interestingly, $\mathrm{Cl}$ is also identified in some locations in layer 2 of the corrosion product, probably in association with the alloying elements $\mathrm{Fe}, \mathrm{Cr}$ and $\mathrm{Ni}$. In some locations (micrographs not shown here), $\mathrm{Cl}$ rich features were observed to have precipitated from some positions in layer 2. The EDS maps in 
Figure 3 also show that both $\mathrm{Cr}$ and $\mathrm{O}$ were the predominant elements on locations that seem to mark the grain boundaries (although samples were not etched), hence suggesting that the grain boundaries were attacked.

In Figures 4-6, results from the plan view 'top-down' characterization are presented. Because the deposit could be lifted up from the sample surface as a compact layer, it was examined from both the gas/deposit and the deposit/corrosion product interfaces; in contrast, these interfaces are usually damaged during preparation of a sample cross-section. Plan view characterization of the deposit both from the gas/deposit and deposit/corrosion product interfaces showed no additional features on the deposit particles (Figure 4) and EDS analysis also confirmed that the deposit contains only $\mathrm{Cl}$ (52.5 wt \%) and K (47.6 wt \%) after the exposure. The micrographs in Figure 5 show the topography of layer 1 of the corrosion product after removal of the deposit. Corrosion products on the surface of layer 1 are observed as heterogeneous protrusions, mostly around the deposit particles. EDS analysis suggests that these protrusions existed in two kinds:

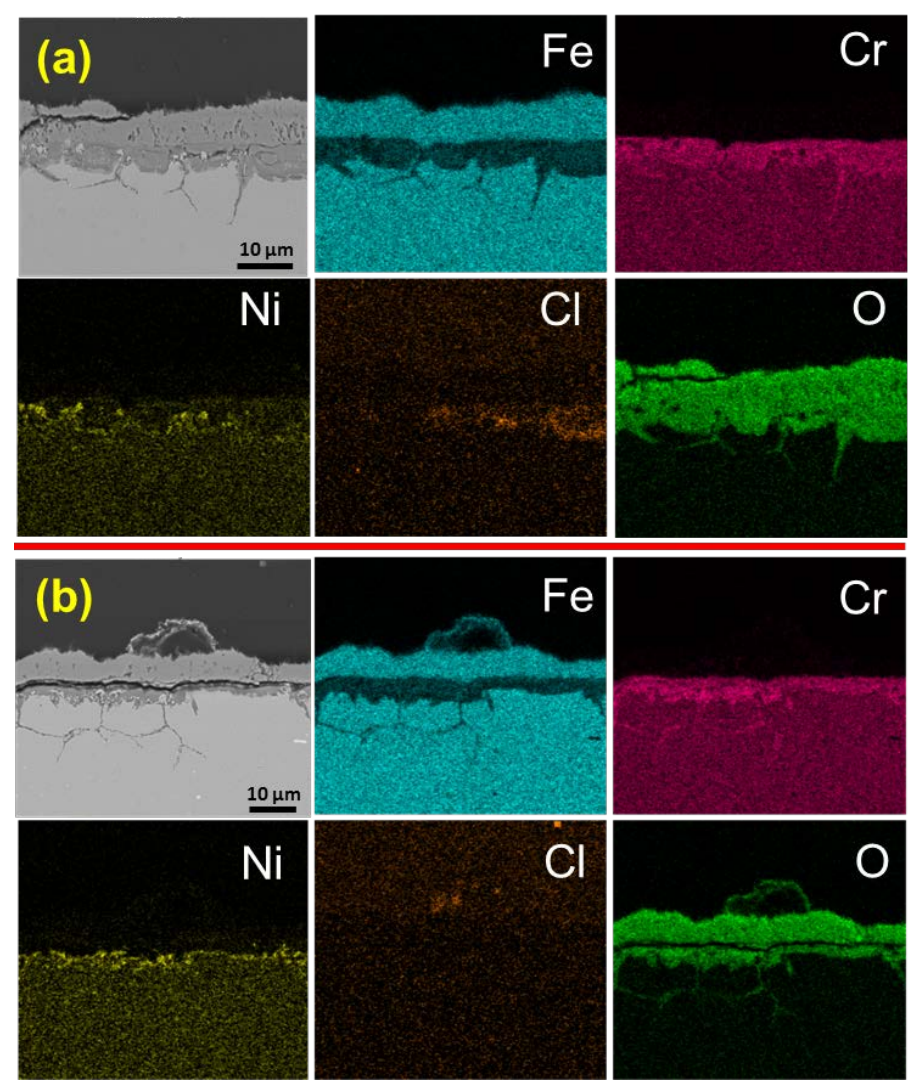

Figure 3. EDS maps showing the distribution of various elements in different regions (a) and (b) (cf. Figure 2) of the corrosion products on deposit-coated samples exposed to an oxidizing gas mixture (i.e. experimental condition Ia). 


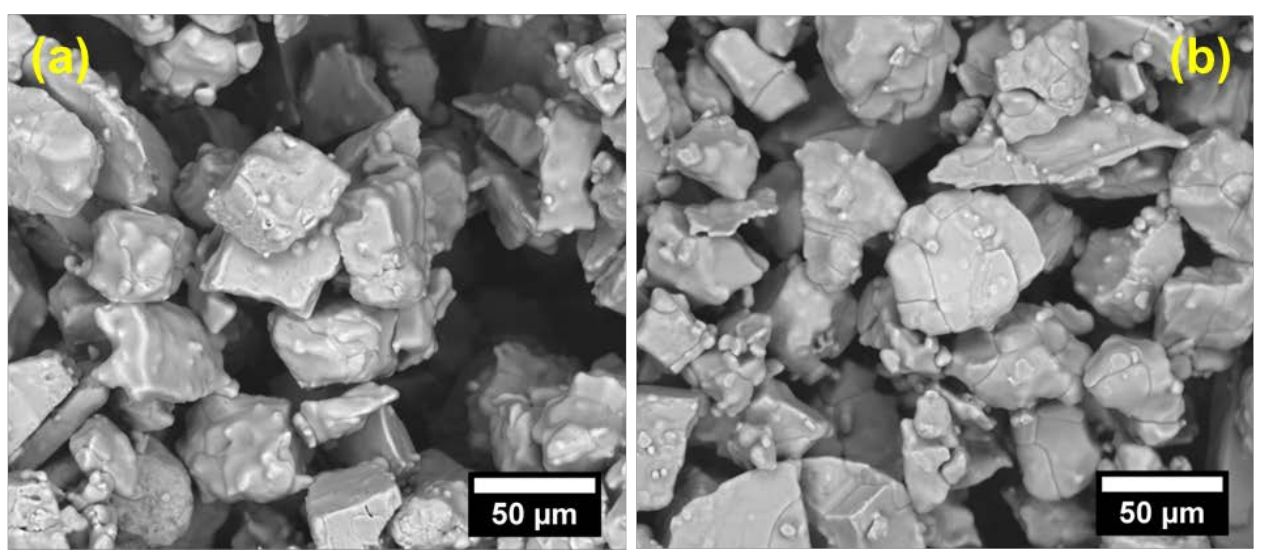

Figure 4. Plan-view microstructure of deposit particles observed from the (a) gas/deposit interface and (b) deposit/corrosion product interface after removal of the deposit, after exposure to an oxidizing gas mixture (experimental condition Ia).

(i) Fe-rich oxide (Figure 5a) and (ii) K-Cl-Fe-O rich accumulations (Figure 5b). Consistent with the elemental analysis, the contrast observed in the micrographs also suggests a difference in elemental composition of the accumulations. In the $\mathrm{K}-\mathrm{Cl}-\mathrm{Fe}-\mathrm{O}$ rich accumulations, the small particles exhibit the same contrast as the $\mathrm{KCl}$ particles, compared with the surrounding features which appear brighter. In Figure 5c, these K-Cl-Fe-O features are observed to accumulate around the deposit particles. Conversely, Figure 5d shows that some regions of layer 1 existed as a compact Fe-rich oxide layer, consistent with the compact layer shown in Figure 2a. 

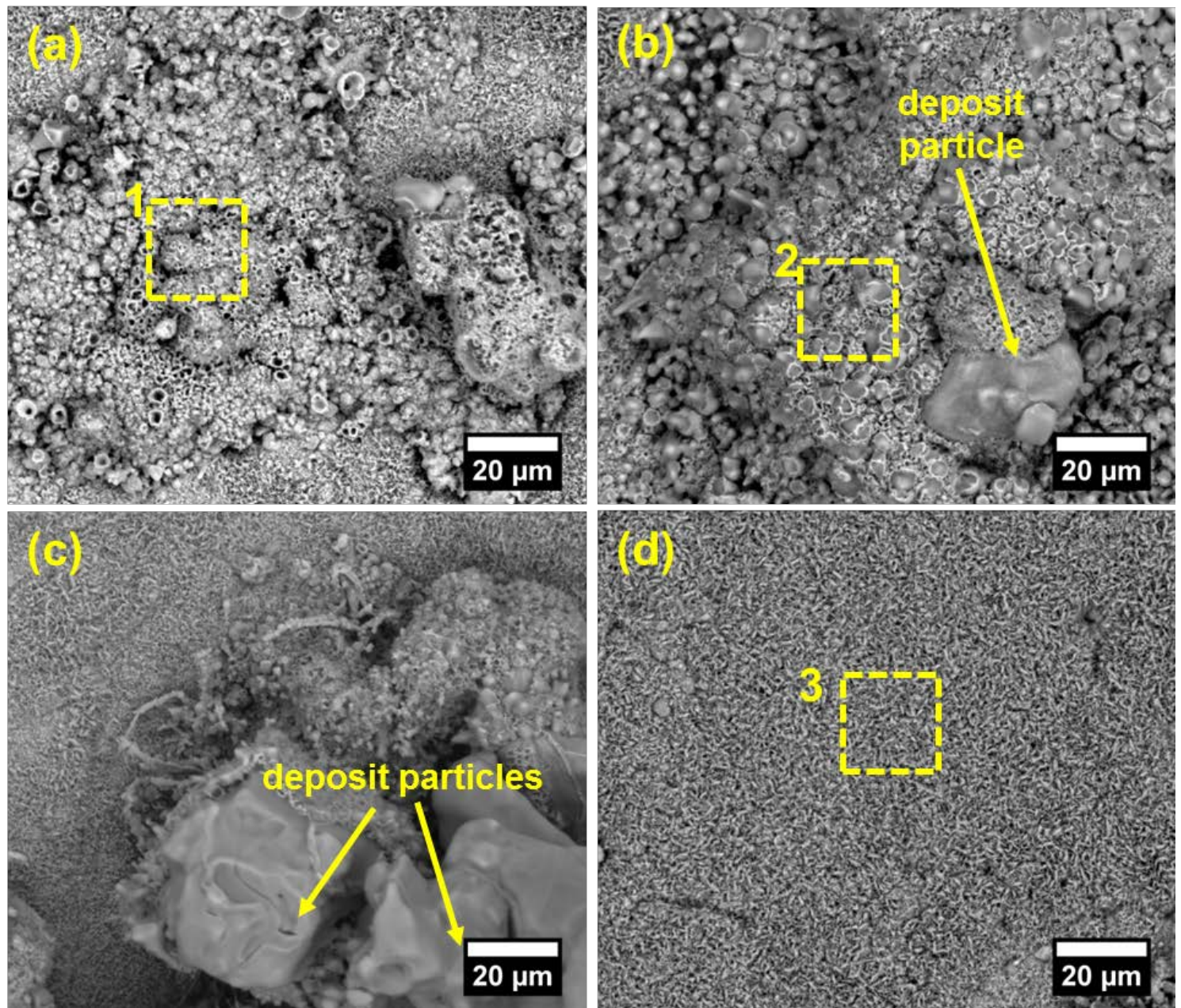

Figure 5. Plan view micrographs showing layer 1 of corrosion products on a sample exposed to the oxidizing gas mixture (experimental condition Ia) after removal of the deposit. (a-c) indicate heterogeneous regions of the corrosion product, and (d) compact region of the corrosion product. Elemental composition of the selected areas in wt\% is: Region 1: O-27.2, K-3.5, Cr-2.8, Mn-3.4 and Fe-61.2. Region 2: O-25.7, Cl-14.2, K-15.4, Cr-2.3, Mn-2.1 and Fe-39.7. Region 3: O-27.5, Cr-1.3, Mn-2.1 and Fe-68.3. 


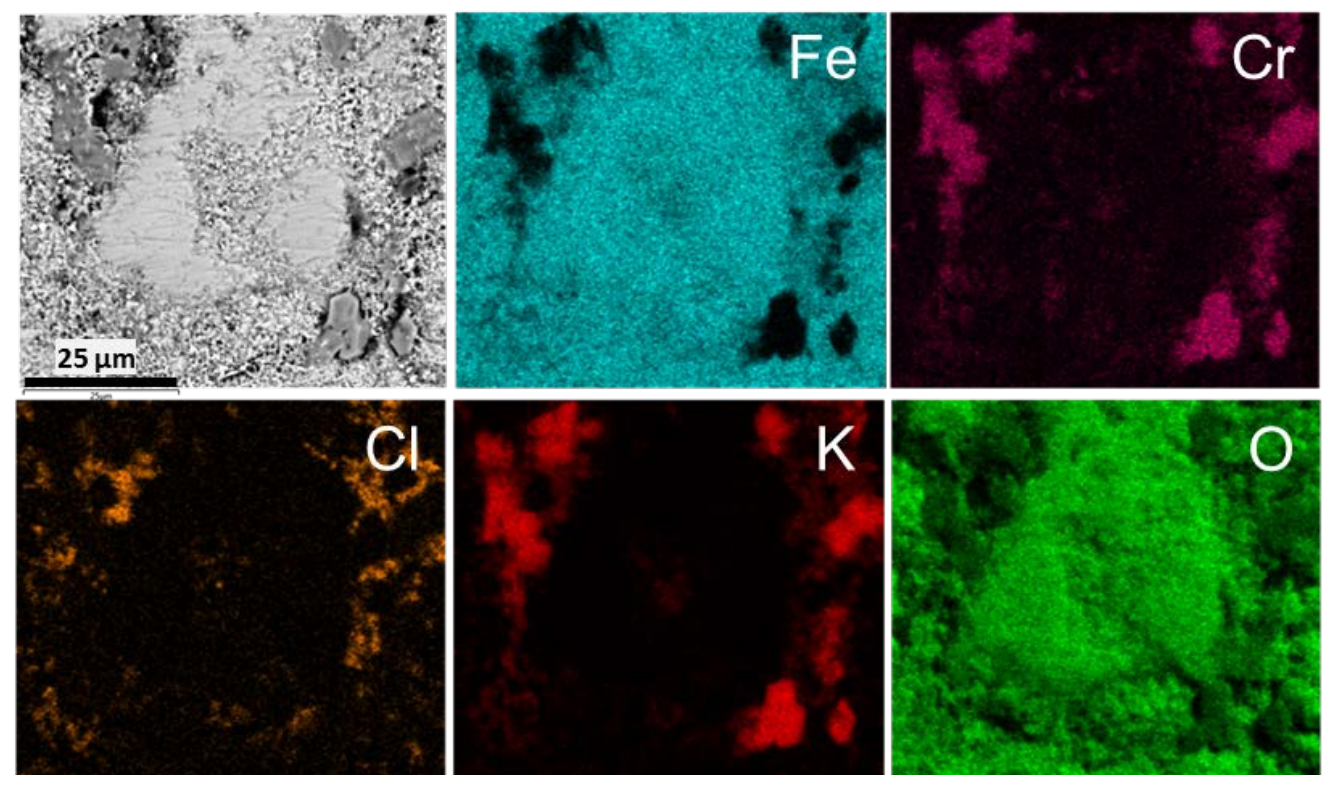

Figure 6. Plan view micrograph and EDS of corrosion products (experimental condition Ia) observed after partial removal of layer 1 .

The corrosion product layer observed after partial removal of layer 1 (Figure 6) still showed the presence of $\mathrm{Fe}$ and $\mathrm{O}$. In addition, some local features rich in $\mathrm{Cr}$ and $\mathrm{K}$ as well as $\mathrm{Cl}$ were also observed. The identification of $\mathrm{K}$ and $\mathrm{Cr}$ indicates the presence of $\mathrm{K}_{2} \mathrm{CrO}_{4}$, which is likely to form under experimental condition Ia [18,41]. With further removal of layer 1 , the Cr-rich inner layer of the corrosion product (layer 2) is observed as shown in Figure 7a. In line with observations from cross-sections (Figure 3), $\mathrm{Cl}$ rich features were also observed on some locations in this layer. The elemental maps in Figure 7a show that layer 2 consists of $\mathrm{Cr}, \mathrm{Ni}, \mathrm{Fe}$ and $\mathrm{O}$. Also, Ni is seen to be enriched along the grain boundaries. In larger depth, as observed after continued removal of layer 2, preferential attack along the grain boundaries is observed (Figure 7b). At the corrosion front where grain boundaries have been attacked, EDS maps show that $\mathrm{Cr}$ and $\mathrm{O}$ are enriched along such grain boundaries.

Figure 8 shows results from GI - XRD measurements, recorded with successive mechanical removal of the corrosion product layers. The diffractogram recorded on layer 1 reveals that $\mathrm{Fe}_{2} \mathrm{O}_{3}$ (Joint Committee on Powder Diffraction Standards, JCPDS card 33-664) and KCl (JCPDS card 41-1476) are the crystalline phases present in this layer of the corrosion product. $\mathrm{Fe}_{2} \mathrm{O}_{3}$ and spinel $-\mathrm{FeCr}_{2} \mathrm{O}_{4}$ (JCPDS card 34-140) are phases identified after partial removal of layer 1, as well as in layer 2 . When the region of grain boundary attack is approached, the spinel phase and austenite phase (JCPDS card 33-397) become the only identifiable phases in the diffractogram, while the latter phase predominates as the corrosion front/bulk alloy is reached. 

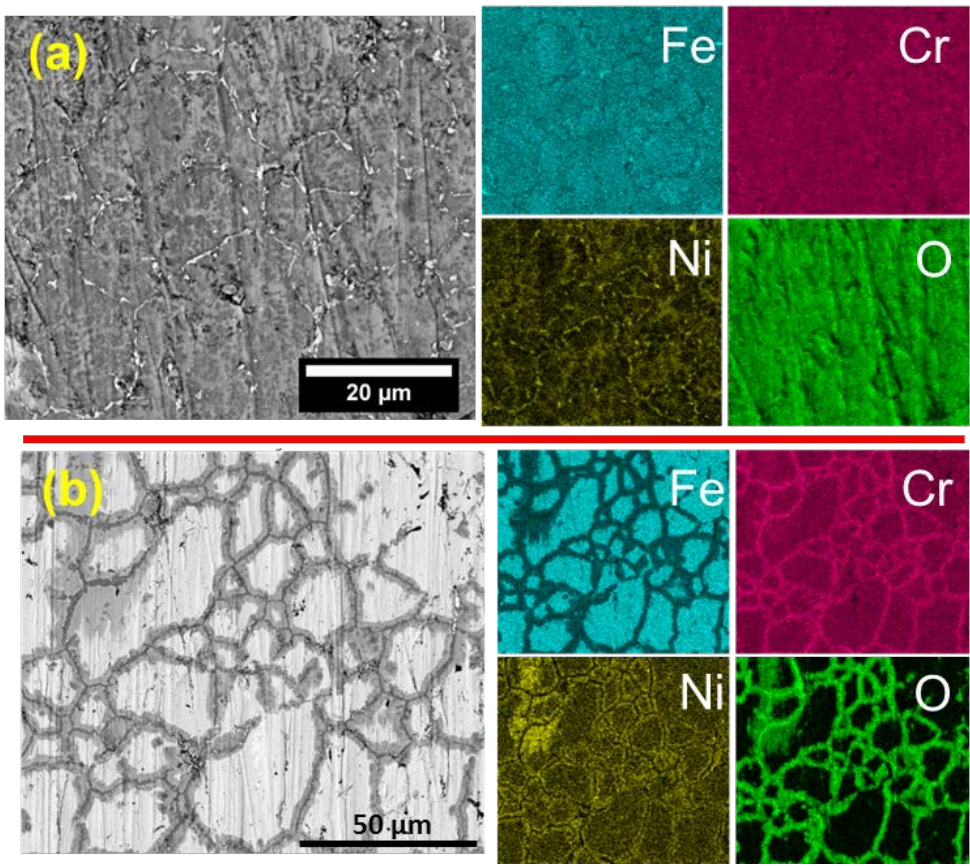

Figure 7. Plan-view micrographs and EDS elemental maps of (a) layer 2 of corrosion product and (b) the region of grain boundary attack close to the corrosion front after removal of layer 2 on a sample exposed to an oxidizing gas mixture (experimental condition Ia).

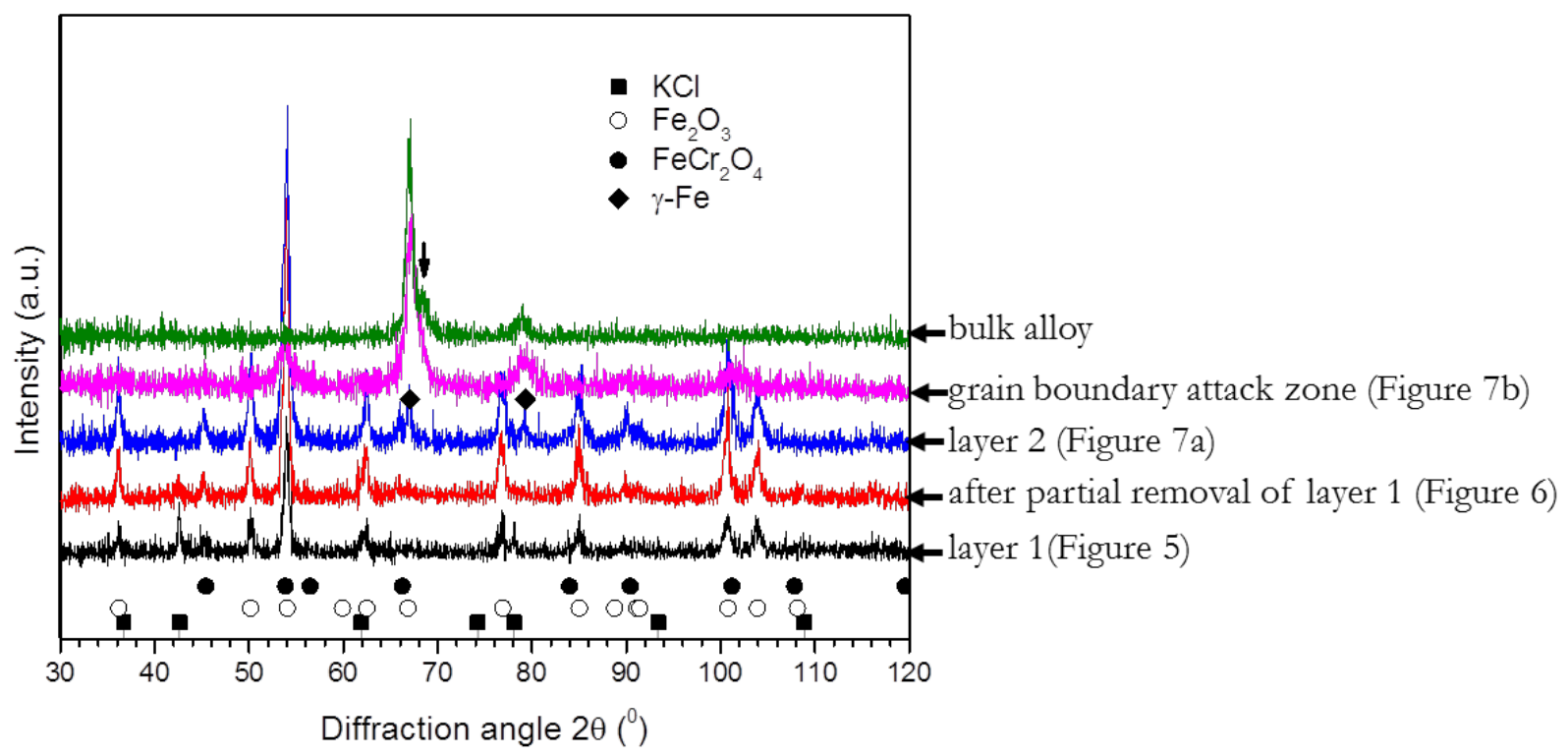

Figure 8. X-ray diffractograms showing the crystalline phases in the various layers of the corrosion product on a deposit-coated sample exposed to an oxidizing gas mixture (experimental condition Ia). The peak at $68^{\circ} 2 \theta$ (see arrow) corresponds to $\alpha^{\prime}$-Fe, which originates from a phase transformation of $\gamma$-Fe due to mechanical removal of the bulk alloy. 
A double layered oxide was observed on the deposit-free samples after exposure to an oxidizing gas mixture, and there was no grain boundary attack (Figure 9a). The thickness and continuity of the outer and inner layer (layers 1 and 2, respectively) varied along the sample surface. The plan view micrograph in Figure $9 \mathrm{~b}$ also confirms the discontinuous nature of the corrosion product. EDS elemental mapping on the cross section revealed that the outer layer (layer 1) is enriched in Fe and $\mathrm{O}$ while $\mathrm{Cr}$ and $\mathrm{O}$ become predominant in the inner layer (layer 2). Additionally, $\mathrm{Ni}$ is observed in the lower part of layer 2, and is enriched at its interface with the alloy bulk. At the discontinuous regions of the corrosion product, localized $\mathrm{Cr}$ enriched oxide is noticed above the alloy bulk. This is consistent with the plan view elemental mapping (Figure 9b), revealing $\mathrm{Cr}$ to be enriched at the interface between the Fe rich oxide islands.

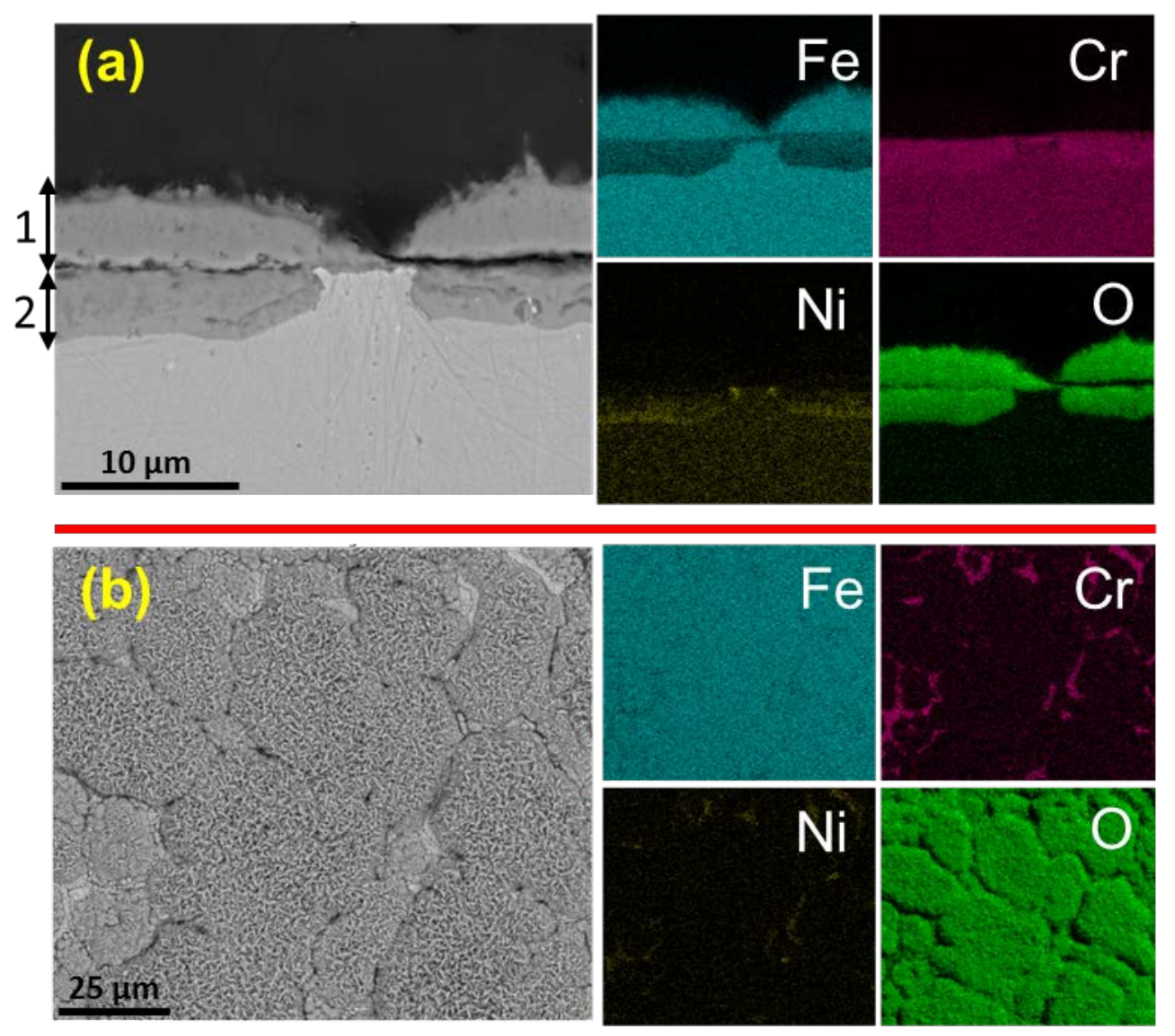

Figure 9. (a) Cross-section and (b) plan-view micrographs with corresponding EDS maps showing elemental composition of the corrosion products resulting from exposure of deposit-free sample to an oxidizing gas mixture (i.e. experimental condition Ib). Double-headed arrows (1) and (2) indicate the different layers of corrosion product.

Results from GI - XRD measurements on the deposit-free sample exposed to an oxidizing gas mixture are shown in Figure 10. The identified crystalline phases are $\mathrm{Fe}_{2} \mathrm{O}_{3}$ (JCPDS card 33-664) and $\mathrm{FeCr}_{2} \mathrm{O}_{4}$ (JCPDS card 34-140). The austenite peaks present in the diffractogram are attributed to the alloy bulk, which contributes to diffraction due to the thin corrosion product. 


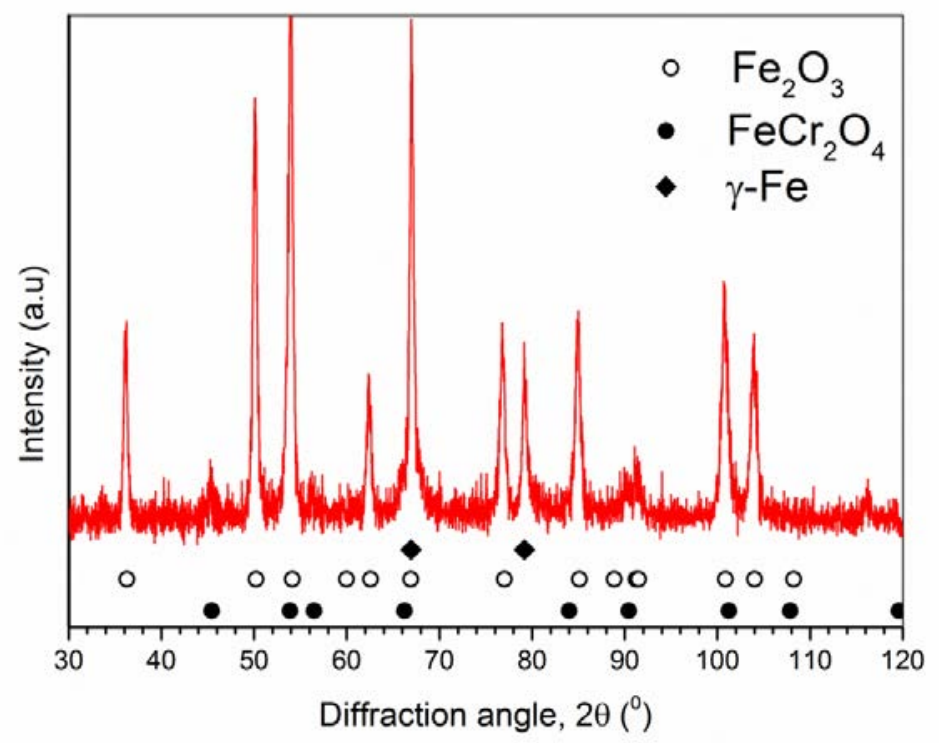

Figure 10. X-ray diffractogram showing the predominant crystalline corrosion product phases on a deposit-free sample exposed to an oxidizing gas mixture (experimental condition Ib).

\subsection{Deposit $(\mathrm{KCl})$ coated samples exposed to an oxidizing-chlorinating gas mixture} (Experiment IIa)

The micrographs in Figure 11 show the typical cross-sections of deposit-coated samples, after exposure to an oxidizing-chlorinating gas mixture (i.e. experimental condition IIa in Table 1). Generally, three layers can be observed from the cross sections: layer 1 (in Figure 11a) is a very inhomogeneous and porous upper layer observed on some regions of the exposed sample, while it was absent on other locations on the sample (cf. Figure 11b). Layer 2 (in Figure 11a and b) is a compact layer which partly cracked during metallographic sample preparation. Layer 3 (in Figure 11b) refers to localized selective attack together with further attack along grain boundaries of the alloy. The predominant elements in these 3 layers are shown by EDS maps in Figure 12. In layer 1 of the corrosion products, $\mathrm{Fe}$ and $\mathrm{O}$ are the predominant elements, with some $\mathrm{Mn}$ and $\mathrm{Ni}$. $\mathrm{K}$ and $\mathrm{Cl}$ are identified in localized areas. Layer 2 is enriched in $\mathrm{Cr}$ and $\mathrm{O}$. In the regions designated as layer 3 of the corrosion product, there is localized depletion of $\mathrm{Fe}$ and $\mathrm{Cr}$, with a corresponding enrichment of $\mathrm{Ni}$ in these areas. Regions that suffered grain boundary attack contained $\mathrm{Cr}, \mathrm{Ni}, \mathrm{Cl}$ and $\mathrm{O}$ (Figure 12b). 


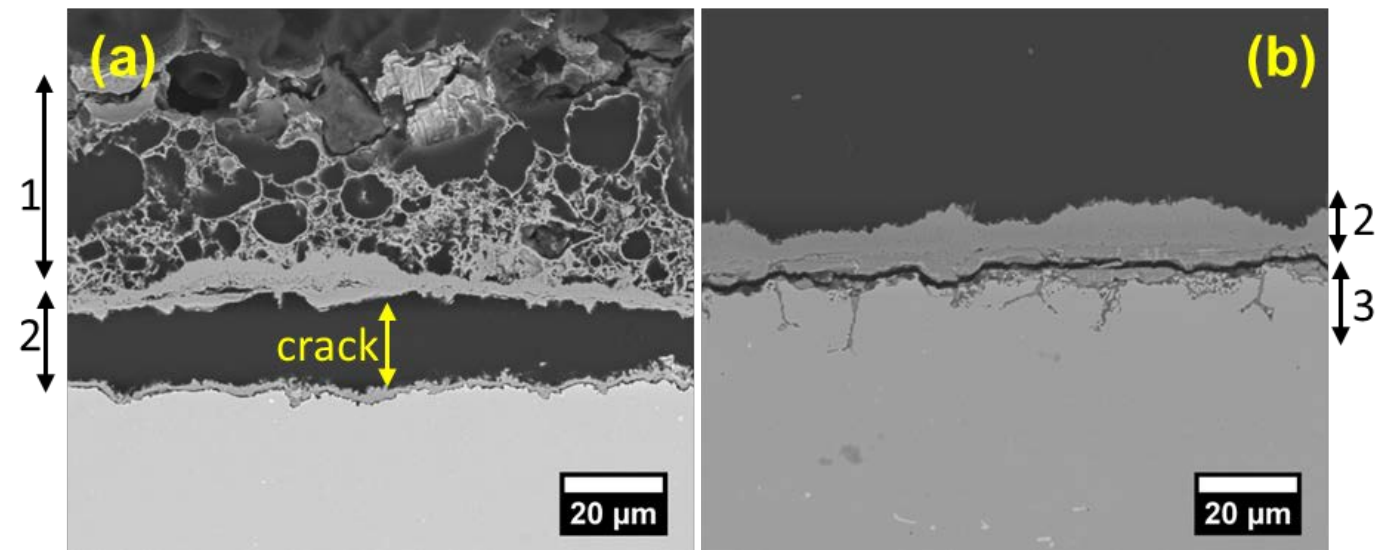

Figure 11. Cross-sections showing the corrosion product on deposit-coated sample exposed to an oxidizing-chlorinating gas mixture (i.e. experimental condition IIa). (a) Regions with bubble-like heterogeneous morphology and (b) relatively compact layers of corrosion product. Double-headed arrows 1,2 and 3 indicate the different layers of corrosion product.
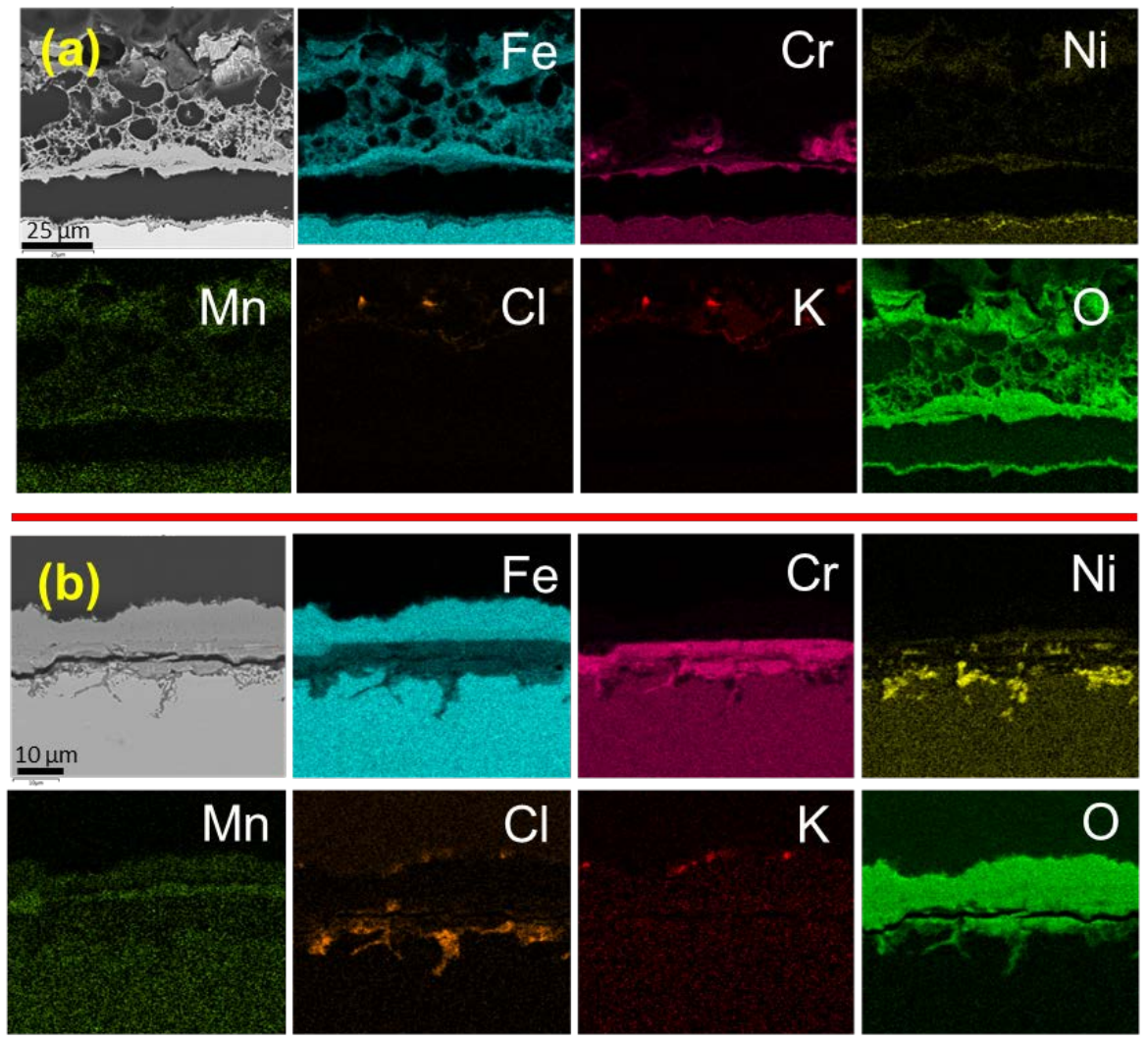

Figure 12. EDS maps showing the elemental composition of the corrosion products (cf. Figure 11) resulting from exposure of deposit-coated samples to an oxidizing-chlorinating gas mixture (i.e. experimental condition IIa).

In Figures 13 and 14, selected results from the plan view 'top-down' characterization are presented. At the gas/deposit interface (Figure 13a), the initial deposit of $\mathrm{KCl}$ is observed to retain its morphology, and only $\mathrm{K}$ and $\mathrm{Cl}$ were identified by EDS analysis. In contrast, at the deposit/corrosion 
product interface, the deposit appears to have partially melted because the facetted appearance is replaced by a smooth surface (Figure 13b). Additionally, some particles are observed to have accumulated on the deposit. EDS analysis at the deposit/corrosion product interface showed the deposit to contain (in wt \%): $\mathrm{Fe}-5.2, \mathrm{O}-9.8, \mathrm{Cl}-43.2$ and $\mathrm{K}-41.8$.
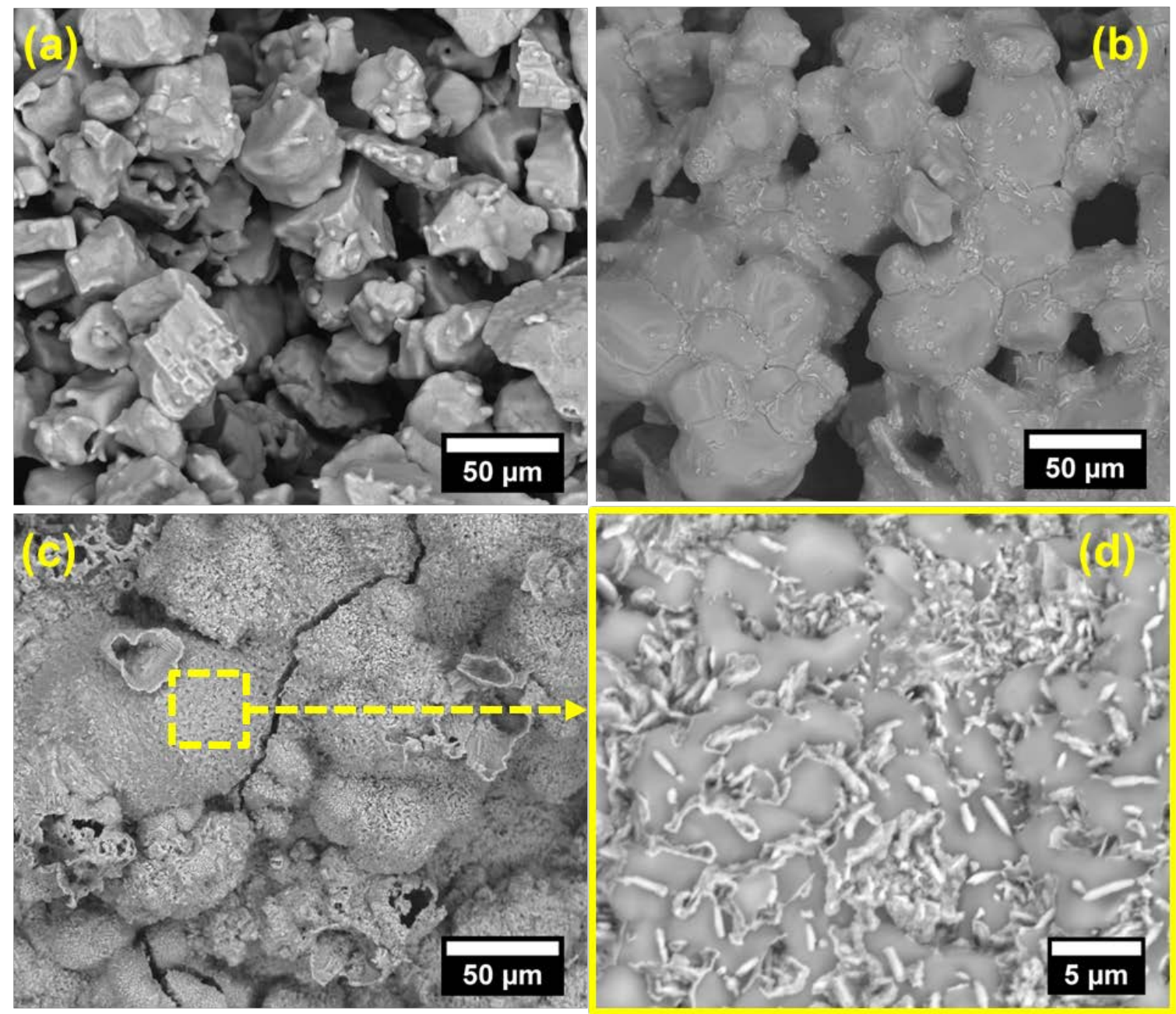

Figure 13. Plan view microstructure after exposure of deposit-coated samples to an oxidizingchlorinating gas mixture (experimental condition IIa) showing the deposit at (a) the gas/deposit interface and at (b) the deposit/corrosion product interface. (c and d) correspond to layer 1 of corrosion product observed below the initial deposit.

Figure 13c shows the plan view microstructure of layer 1 of the corrosion product after removal of the deposit. The observed heterogeneous and bubble-like morphology from plan view characterization is consistent with that observed in the cross-section in Figure 11a, and possibly, originates from removal/entrapment of gaseous species below this layer. Layer 1 consists of a mixture which contains a molten phase as revealed from the magnified micrograph in Figure 13d. EDS analysis showed that in addition to metal oxides of $\mathrm{Fe}, \mathrm{Cr}$ and $\mathrm{Mn}$, the mixture also contained $\mathrm{K}$ and 
$\mathrm{Cl}$ in the following concentration (in wt \%): $\mathrm{Fe}-33.7, \mathrm{Mn}-4.9, \mathrm{Cr}-1.6, \mathrm{O}-20.2, \mathrm{Cl}-20.0$ and $\mathrm{K}$ -19.6 .
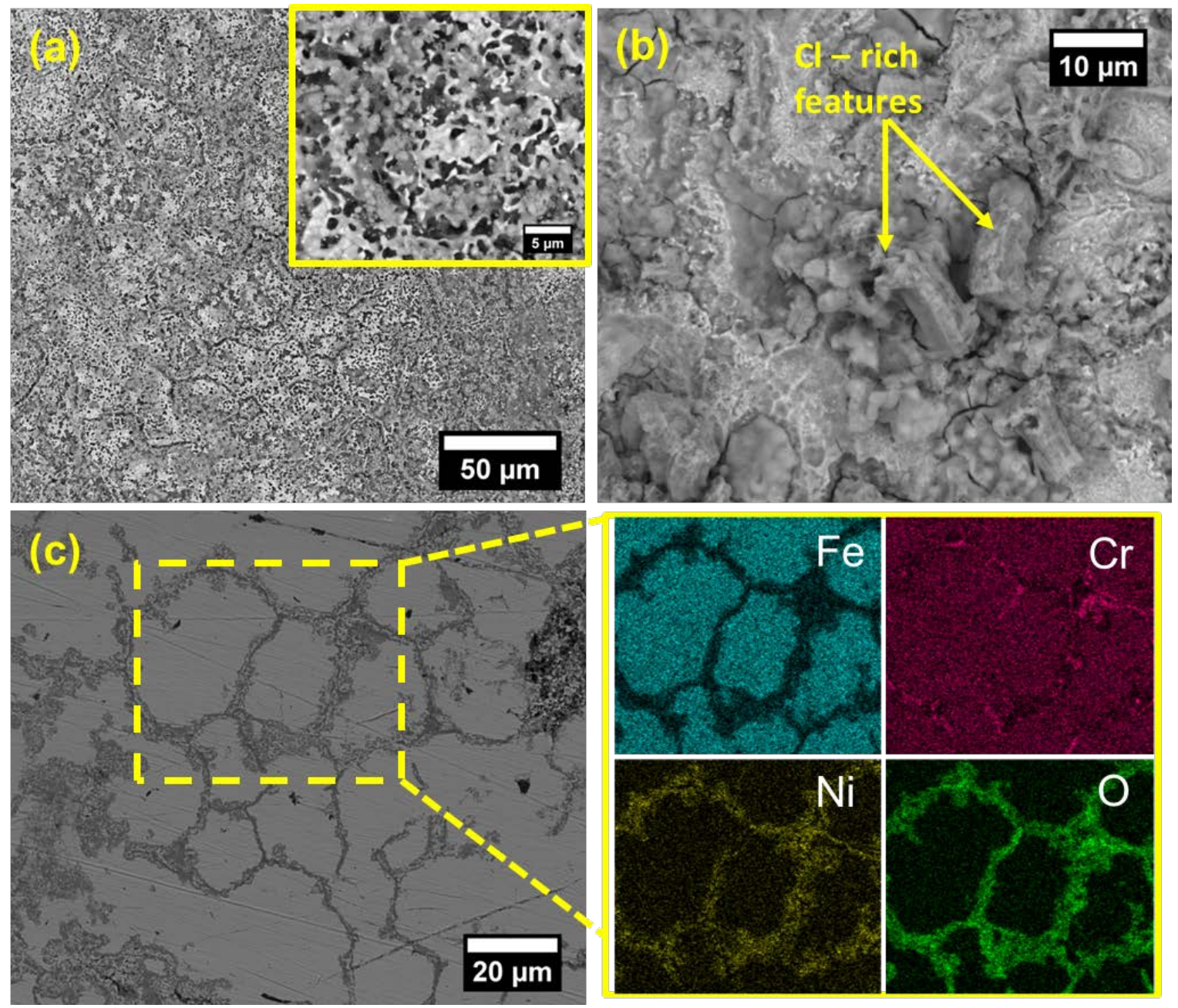

Figure 14. Plan view microstructure of layer 3 showing (a) the Ni rich layer resulting from selective attack, (b) $\mathrm{Cl}$ rich structures observed on some locations in layer 3. Grain boundary attack and the elemental composition close to the corrosion front is shown in (c). The sample was exposed to an oxidizing-chlorinating gas mixture (experimental condition IIa).

The plan view micrographs in Figure 14 show the microstructure of layer 3. Figure 14a clearly shows that this layer was very porous with a corresponding elemental composition of (in wt \%): $\mathrm{Ni}-64.6$, $\mathrm{Fe}-14.7, \mathrm{Cr}-7.2 \mathrm{Si}-1.5$ and $\mathrm{O}-9.8$. At some locations on this layer, $\mathrm{Cl}$ containing protrusions were observed (Figure 14b). Elemental analysis on these features revealed the following composition (in wt \%): $\mathrm{Ni}-17.1, \mathrm{Fe}-34.9, \mathrm{Mn}-1.1, \mathrm{Cr}-8.3, \mathrm{O}-24.4$ and $\mathrm{Cl}-14.1$. At positions close to the corrosion front, as revealed by further removal of the corrosion product, the corrosion attack is observed to proceed preferentially along the grain boundaries (Figure 14c). EDS maps show that Cr, $\mathrm{Ni}$ and $\mathrm{O}$ are enriched along the grain boundaries whereas $\mathrm{Fe}$ is depleted. 
X-ray diffractograms showing the major crystalline phases of the corrosion products are presented in Figure 15. Measurements on layer 1 of the corrosion product (Figure 13c) detected the crystalline phases $\mathrm{Fe}_{2} \mathrm{O}_{3}$ (JCPDS card 33-664), $\mathrm{FeCr}_{2} \mathrm{O}_{4}$ (JCPDS card 34-140) and $\mathrm{KCl}$ (JCPDS card 41-1476). Whether or not other alloying elements are in solid solution with identified phases cannot be determined, because the observed slight offset of measured peak positions compared to the theoretical ones can originate from both chemical variations and internal stresses.

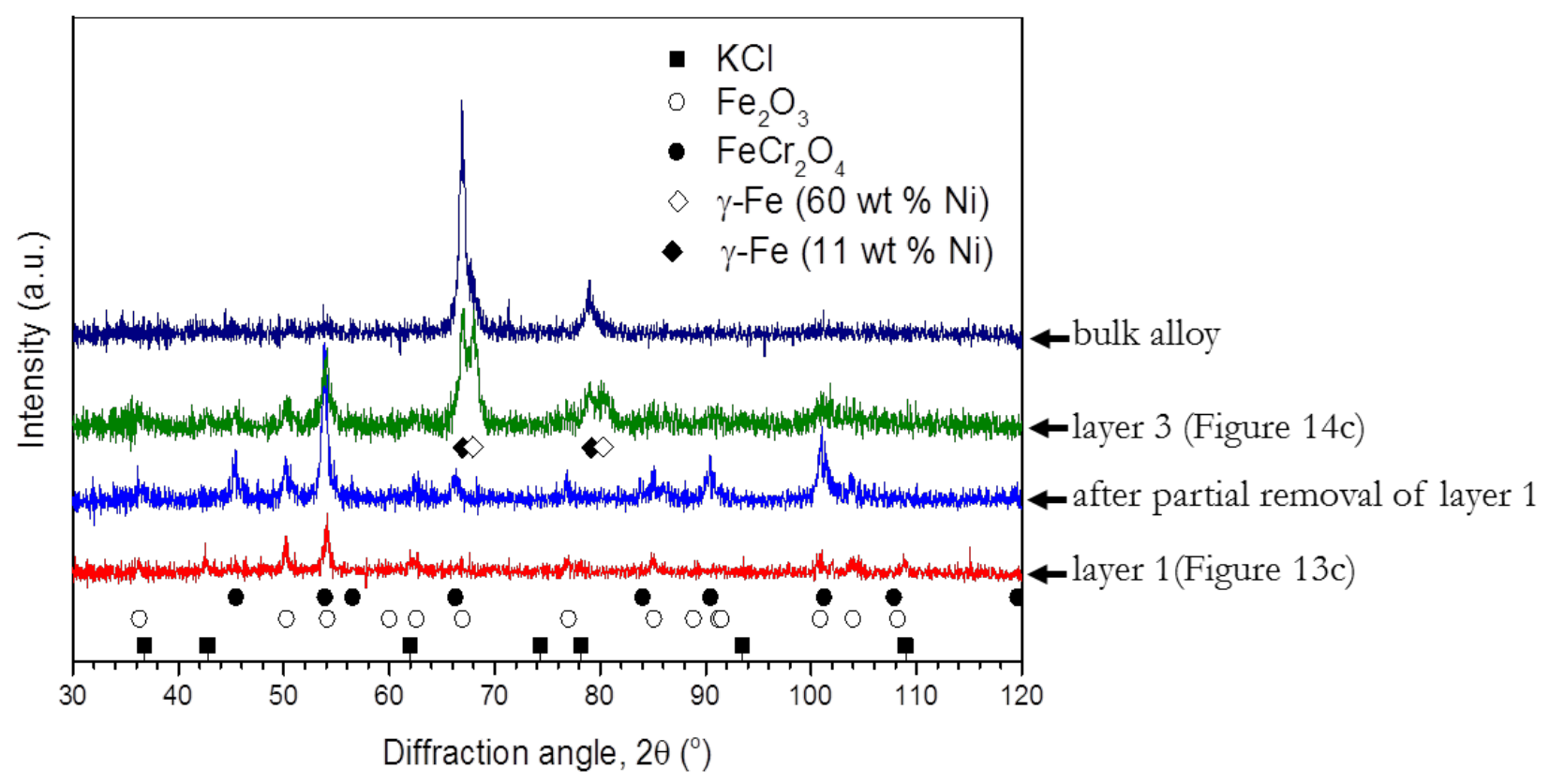

Figure 15. X-ray diffractograms showing the predominant crystalline phases in different layers of corrosion product after exposure of a deposit-coated sample to an oxidizing-chlorinating gas mixture (experimental condition IIa).

On layer 3 (the porous Ni rich layer), two austenite phases (JCPDS cards 33-397 and 33-945) are observed in the diffractogram. One of them originates from austenite containing about $75 \mathrm{wt} \%$ of $\mathrm{Ni}$ and corresponds to the high concentration of Ni identified in layer 3 by EDS analysis. Solid solution of $\mathrm{Ni}$ in austenite should provoke an increase in lattice constant [45] which would shift the $(\gamma$-Fe-75 $\mathrm{wt} \% \mathrm{Ni}$ ) peaks to a lower $2 \theta$ value. However, because this effect reverses at higher Ni concentrations ( $>40 \mathrm{wt} \% \mathrm{Ni}$ ) [46], the actual Ni concentration in layer 3 (64.6 wt. \% Ni) shifts the peak of $(\gamma$-Fe$75 \mathrm{wt} \% \mathrm{Ni}$ ) to higher $2 \theta$ values relative to that of ( $\gamma$-Fe-11 wt $\% \mathrm{Ni}$ ) (Figure 15). As the corrosion front is approached, only peaks originating from austenite with $11 \mathrm{wt} \% \mathrm{Ni}$ (JCPDS card 33-397), corresponding to the bulk alloy, are recorded by XRD.

\subsection{Deposit-free samples exposed to an oxidizing-chlorinating gas mixture (Experiment IIb)}

High temperature corrosion of deposit-free samples under an oxidizing-chlorinating gas mixture did not result in formation of heterogeneous corrosion products as observed on deposit-coated samples 
(cf. Figures 16 and 11a). Instead, after the exposure of deposit-free samples, a double layered corrosion product formed (Figure 16a).

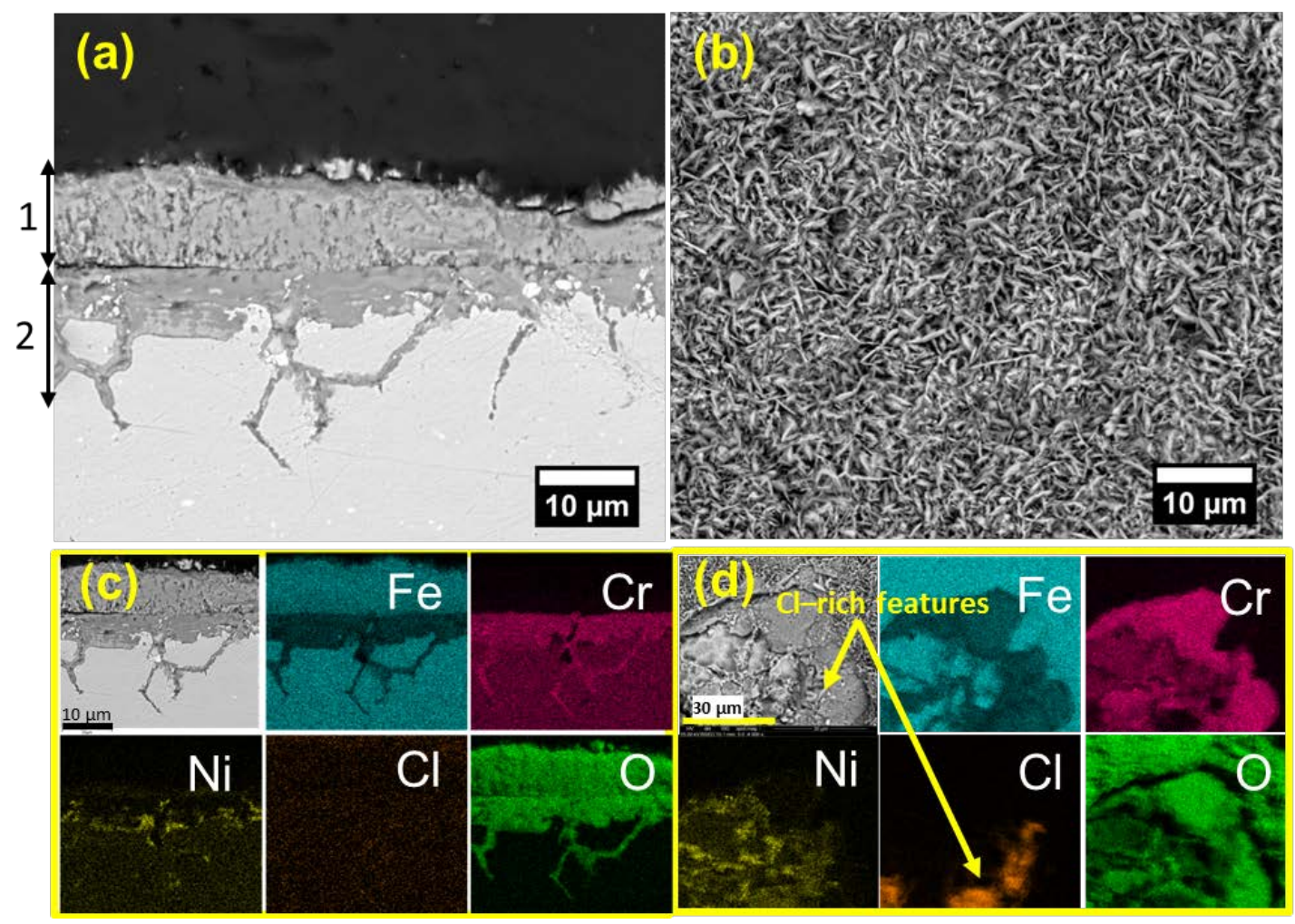

Figure 16. Corrosion products after exposure of deposit-free samples to an oxidizing-chlorinating gas mixture (experimental condition IIb). (a) Cross-section and (b) plan-view micrograph. (c) Crosssection EDS maps showing elemental composition of the corrosion products. (d) Plan view EDS maps showing elemental distribution below a spalled region. Double-headed arrows 1 and 2 indicate the different layers of corrosion product.

Corrosion attack under this condition is seen to progress into the bulk of the alloy in the form of grain boundary attack. EDS maps in Figure 16c reveal that the double layered corrosion product is enriched in $\mathrm{Fe}$ and $\mathrm{O}$ in the outer layer, layer 1, whereas $\mathrm{Cr}$ and $\mathrm{O}$ become predominant in the inner layer, layer 2. It is also observed that $\mathrm{Ni}$ is enriched in the lower parts of layer 2 which extends into regions of grain boundary attack, enriched in $\mathrm{Cr}$ and $\mathrm{O}$. Additionally, Ni enrichment is observed adjacent to the regions where grain boundary attack occurred.

Similar to the observation on the sample cross-section, plan view investigation (Figure 16b) did not reveal any heterogeneous layer of corrosion product. Instead, the corrosion products consisted of blade like structures on the sample surface (similar to Figure 5d and 9b). EDS analysis on regions where the corrosion product partly spalled off (Figure 16d) confirm the double layer formation of an outer Fe-O layer, and an inner Cr-O rich layer (i.e. layer 1 and layer 2, respectively). Interestingly, $\mathrm{Cl}$ rich features were also observed around the interface between layer 2 and the bulk alloy. 
From qualitative phase analysis using GI-XRD (Figure 17), $\mathrm{Fe}_{2} \mathrm{O}_{3}$ (JCPDS card 33-664) and $\mathrm{FeCr}_{2} \mathrm{O}_{4}$ (JCPDS card 34-140) were the major crystalline corrosion products identified on the deposit-free sample exposed to the oxidizing-chlorinating gas mixture. The additional presence of $\mathrm{Fe}_{3} \mathrm{O}_{4}$ (JCPDS card 73-698) is likely, but its theoretical peak positions are close to the ones for $\mathrm{FeCr}_{2} \mathrm{O}_{4}$, moreover, the solubility of $\mathrm{Cr}$ in iron oxides may favour formation of $\mathrm{FeCr}_{2} \mathrm{O}_{4}$.

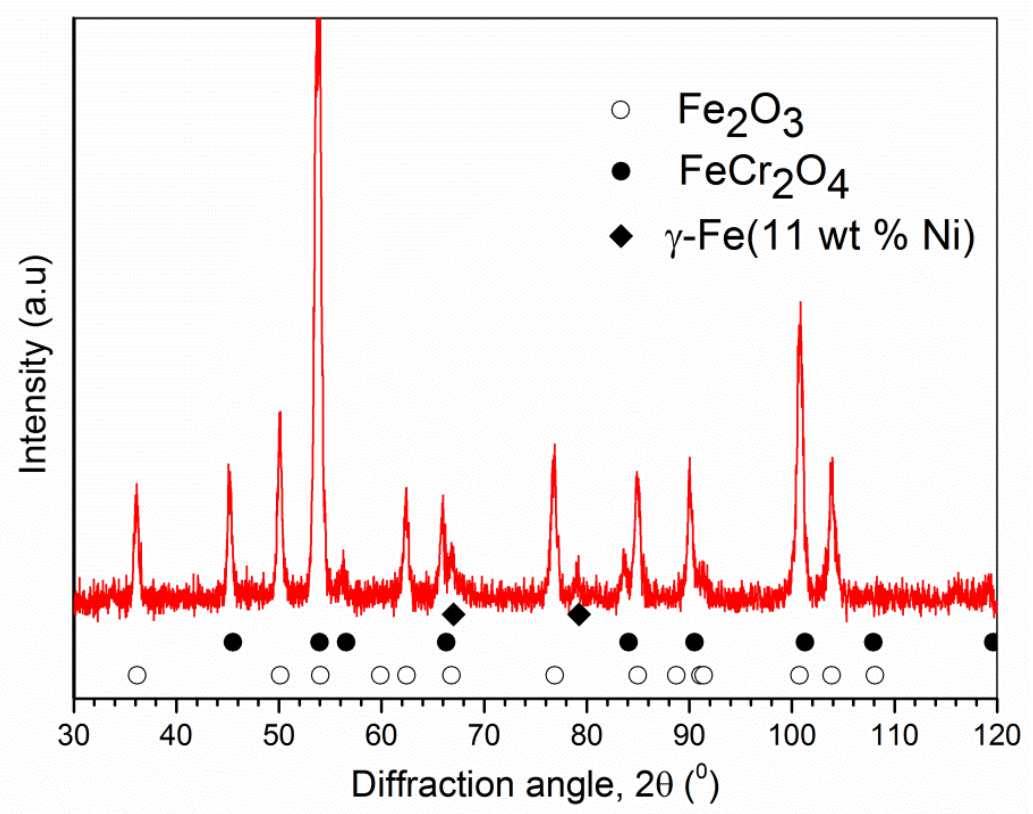

Figure 17. X-ray diffractogram showing the crystalline corrosion product phases on a deposit-free sample exposed to an oxidizing-chlorinating gas mixture (experimental condition IIb).

\subsection{Extent of corrosion attack}

For comparison of the corrosion attack on deposit-coated and deposit-free samples after exposure to the different gas mixtures, the depths of the internal attack (thicknesses of layer 2 or 3, or the total thicknesses of layer 2 and 3) were measured on more than 20 positions on each of the exposed samples. The measurement considered the depth of the observed internal and/or grain boundary attacked regions on the specimens (depending on the exposure condition and the resulting corrosion product, cf. Figures 2, 9, 11 and 16a) because these layers formed below the original metal interface. The box chart in Figure 18 presents the statistical distribution of measured thicknesses (note the difference in scale). Generally, it is observed that a deeper internal attack occurred on deposit-coated samples than on deposit-free samples irrespective of the flue gas composition. For the deposit-free samples in particular, the measured mean and maximum thicknesses show that more corrosion attack occurred after exposure to the oxidizing-chlorinating gas mixture. However, in the case of the depositcoated samples, the mean thicknesses of internal/grain boundary attacked regions were similar. The thickness of layer 1 could not be assessed in the same way due to the increased porosity and heterogeneity from interaction between the oxide and the deposit (see Figures 2 and 11). 


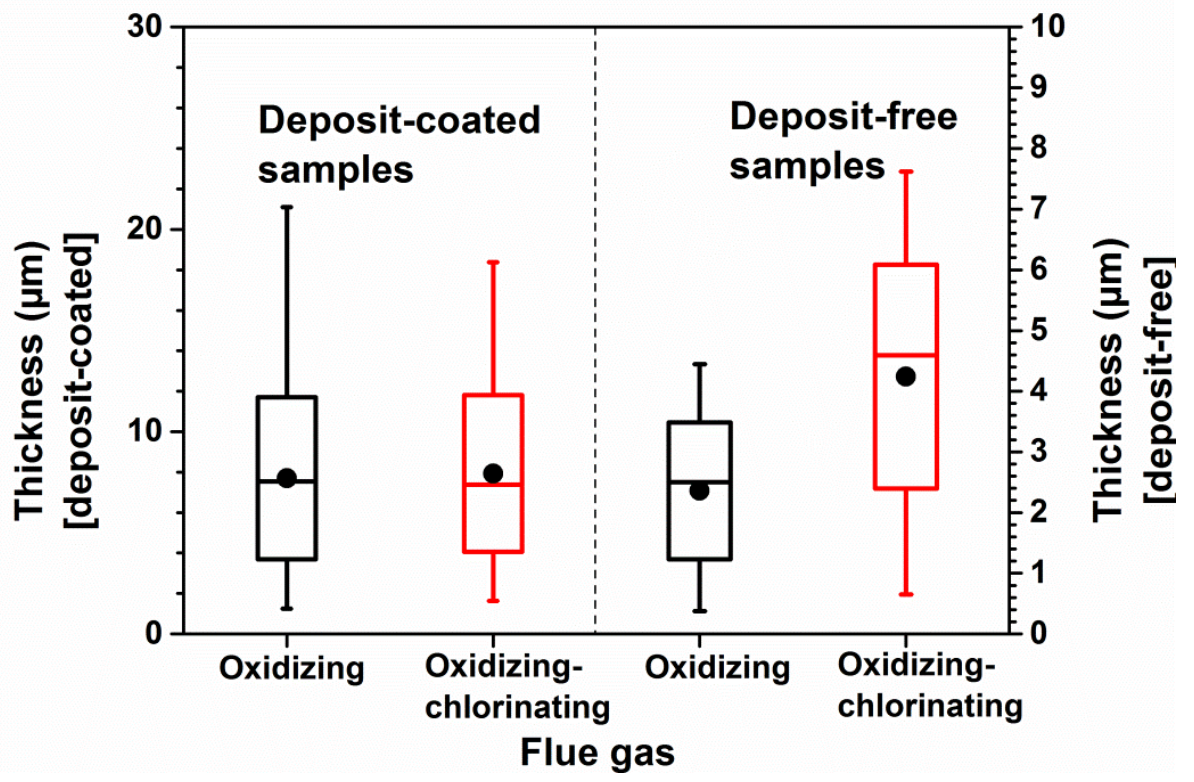

Figure 18. Thicknesses of the resulting internal/grain boundary attack (layers 2 and 3) after exposure to different gas mixtures. The maximum and minimum thicknesses are represented by the marks above and below each box. Location of $50 \%$ of the distribution is shown by the horizontal bar in each box whereas the round dots represent the mean thicknesses. The standard deviation from the mean is represented by the horizontal edges of the box. At least 20 positions on the exposed samples were measured to obtain the distribution.

\section{4}

\section{Discussion}

Experimental results revealed the influence of the gas composition on both the extent of the corrosion attack and the morphology of the various corrosion layers. Generally, severe corrosion was observed on all samples coated with a $\mathrm{KCl}$ deposit, compared to deposit-free samples. In Table 2, the corrosion products observed on deposit-coated and deposit-free samples are summarized.

Table 2. Summary of corrosion products after exposure of deposit-coated and deposit-free samples to the different gas mixtures.

\begin{tabular}{lll}
\hline Experiment & $\begin{array}{l}\text { Deposit } \\
\text { appearance }\end{array}$ & $\begin{array}{l}\text { Corrosion product morphology, phase and } \\
\text { chemical composition }\end{array}$ \\
\hline $\begin{array}{l}\text { Ia (oxidizing } \\
\text { gas mixture) }\end{array}$ & $\begin{array}{l}\text { No observable } \\
\text { change }\end{array}$ & $\begin{array}{l}\text { Layer 1: Compact/partly molten heterogeneous } \\
\left(\mathrm{Fe}_{2} \mathrm{O}_{3}-\mathrm{KCl}\right)\end{array}$ \\
& $\begin{array}{l}\text { Layer 2: } \mathrm{Fe}-\mathrm{Cr}-\mathrm{Ni}-\mathrm{O}\left(\mathrm{Fe}_{2} \mathrm{O}_{3}, \mathrm{FeCr}_{2} \mathrm{O}_{4}\right) . \\
\text { Grain boundary attack, } \mathrm{Cl}-\mathrm{rich} \text { protrusions }\end{array}$ \\
&
\end{tabular}




\begin{tabular}{ll}
\hline Ib (oxidizing gas & Discontinuous double-layered $\left(\mathrm{Fe}_{2} \mathrm{O}_{3}, \mathrm{FeCr}_{2} \mathrm{O}_{4}\right)$ \\
mixture) & Layer 1: $\mathrm{Fe}-\mathrm{O}$ enriched \\
& Layer 2: $\mathrm{Cr}-\mathrm{Ni}-\mathrm{O}$ enriched \\
\hline
\end{tabular}

\begin{tabular}{lll}
\hline $\begin{array}{l}\text { IIa (oxidizing- } \\
\text { chlorinating } \\
\text { gas mixture) }\end{array}$ & $\begin{array}{l}\text { Partly molten at } \\
\text { the } \\
\text { deposit/corrosion } \\
\text { product interface }\end{array}$ & $\begin{array}{l}\text { Layer 1: Mostly partly molten and heterogeneous } \\
\left(\mathrm{Fe}_{2} \mathrm{O}_{3}-\mathrm{KCl}\right) \\
\text { Layer 2: } \mathrm{Fe}-\mathrm{Cr}-\mathrm{O}\left(\mathrm{Fe}_{2} \mathrm{O}_{3}, \mathrm{FeCr}_{2} \mathrm{O}_{4}\right)\end{array}$ \\
& $\begin{array}{l}\text { Layer 3: (Ni-rich }(75 \mathrm{wt} \%) \text { phase). } \\
\text { Grain boundary attack, } \mathrm{Cl}-\text { rich protrusions }\end{array}$ \\
\hline $\begin{array}{l}\text { IIb (oxidizing- } \\
\text { chlorinating gas- } \\
\text { mixture) }\end{array}$ & $\begin{array}{l}\text { Double-layered }\left(\mathrm{Fe}_{2} \mathrm{O}_{3}, \mathrm{FeCr}_{2} \mathrm{O}_{4}\right) \\
\text { Layer 1: } \mathrm{Fe}-\mathrm{O} \text { enriched } \\
\end{array}$ & $\begin{array}{l}\text { Layer 2: } \mathrm{Cr}-\mathrm{Ni}-\mathrm{O} \text { enriched. } \\
\text { Grain boundary attack, } \mathrm{Cl}-\text { rich accumulations }\end{array}$ \\
\hline
\end{tabular}

For the deposit-coated samples, $\mathrm{Fe}_{2} \mathrm{O}_{3}$ were observed in the first layer of corrosion product (i.e. below the deposit) together with $\mathrm{KCl}$ with a morphology indicating that melting of $\mathrm{KCl}$ had occurred. It is also generally observed that the elemental composition of the second/third layer of corrosion products, the occurrence of grain boundary attack depended on the absence/presence of a deposit as well as the composition of the gas mixture. In addition, the deposit morphology after the exposures depended on the composition of the gas mixture. These experimental results suggest that corrosion was primarily affected by $\mathrm{KCl}$ and secondarily by the additional presence of $\mathrm{HCl}$ in the gas mixture. The impact of these species in relation to the observed corrosion products are discussed in the following sections.

\subsection{The influence of $\mathrm{KCl}$ on the corrosion process}

Results from experiment Ia show that even in the absence of a secondary corrosive species such as $\mathrm{HCl}$ in the gas mixture, the deposit $(\mathrm{KCl})$ can initiate significant corrosion of the alloy (cf. Figures 2, 3 and 9). Corrosion of the deposit-free sample exposed to an oxidizing gas mixture resulted in a discontinuous double-layered corrosion product (Figure 9), and the morphology of such corrosion product is consistent with a solid state diffusion oxidation mechanism (involving $\mathrm{CO}_{2}$ and/or $\mathrm{H}_{2} \mathrm{O}$ ) in which the faster transport of Fe results in an external Fe-rich oxide, while Cr forms an inner oxide layer due to its relatively higher affinity to oxygen as well as its slow diffusion in the spinel phase $[47,48]$. The thinner chromium rich oxide observed in local areas (Figure $9 b$ ) is due to the formation of a $\mathrm{Cr}$ rich oxide as diffusion of $\mathrm{Cr}$ through the grain boundaries is higher than in the bulk grain at lower temperatures similar to that in the present study. Formation of $\mathrm{Cr}_{2} \mathrm{O}_{3}$ hence results in slower oxidation rates in these areas [49].

For the deposit-coated samples, plan view investigation show that heterogeneously distributed $\mathrm{Fe}_{2} \mathrm{O}_{3}$ and $\mathrm{KCl}$ have formed below the initial deposit after exposure to an oxidizing gas mixture. Under oxidizing conditions, potassium from $\mathrm{KCl}$ is capable of disrupting the initial protective $\mathrm{Cr}_{2} \mathrm{O}_{3}$ layer 
on the sample (reaction 1), leading to $\mathrm{Cr}$ depletion and subsequent development of a non-protective layer [33]. The reaction has been reported to be more favourable in the presence of gaseous $\mathrm{KCl}$ [38].

$$
\mathrm{KCl}(\mathrm{s})+\frac{1}{4} \mathrm{Cr}_{2} \mathrm{O}_{3}(\mathrm{~s})+\frac{3}{8} \mathrm{O}_{2}(\mathrm{~g})+\frac{1}{2} \mathrm{H}_{2} \mathrm{O}(\mathrm{g}) \rightleftharpoons \frac{1}{2} \mathrm{~K}_{2} \mathrm{CrO}_{4}(\mathrm{~s})+\mathrm{HCl}(\mathrm{g})
$$

For reaction 1, the Gibbs free energy $\left(\Delta \mathrm{G}^{\circ}\right)$ at $560{ }^{\circ} \mathrm{C}$ is $36.57 \mathrm{~kJ} / \mathrm{mol}(\mathrm{KCl})[43,44]$. This reaction can give a $\mathrm{HCl}$ partial pressure $\left(\mathrm{p}_{\mathrm{HCl}}\right)$ of $6.15 \times 10^{-4}$ atm, which by dissociation according to reaction 2 results in a chlorine partial pressure $\left(\mathrm{p}_{\mathrm{Cl}_{2}}\right)$ of $9.10 \times 10^{-7}$ atm $[43,44]$.

$$
2 \mathrm{HCl}(\mathrm{g})+\frac{1}{2} \mathrm{O}_{2}(\mathrm{~g}) \rightleftharpoons \mathrm{Cl}_{2}(\mathrm{~g})+\mathrm{H}_{2} \mathrm{O}(\mathrm{g})
$$

For reaction 2, the Gibbs free energy $\left(\Delta \mathrm{G}^{\circ}\right)$ at $560{ }^{\circ} \mathrm{C}=-2.37 \mathrm{~kJ} / \mathrm{mol}\left(\mathrm{Cl}_{2}\right)[43,44]$.

Identification of $\mathrm{K}-\mathrm{Cr}$ rich regions in the corrosion products (Figure 6) suggests that reaction 1 indeed occurred and also agrees with results in the literature $[16,18,50]$. The corrosion attack initiated by $\mathrm{K}$ is intensified since $\mathrm{HCl}$ released from (1) can dissociate into $\mathrm{Cl}_{2}$ (reaction 2) and is transported through the porous oxide or via an electrochemical mechanism, to the bulk alloy where it chlorinates the alloying elements (M), according to reaction 3 [29,51].

$$
\mathrm{M}(\mathrm{s})+\mathrm{xCl} \rightleftharpoons \mathrm{MCl}_{\mathrm{x}}(\mathrm{s})
$$

It is worth noting that $\mathrm{KCl}$ itself can also act as a chlorine source according to the electrochemical mechanism described in reference [52]. The transition metal chlorides resulting from reaction 3 generally possess high vapour pressures at high temperatures and are consequently volatile. These species are oxidized to the corresponding metal oxides if they encounter environments containing sufficient amounts of oxygen (according to reaction 4).

$$
\mathrm{yMCl}_{\mathrm{x}}(\mathrm{g})+\frac{\mathrm{z}}{2} \mathrm{O}_{2}(\mathrm{~g}) \rightleftharpoons \mathrm{M}_{\mathrm{y}} \mathrm{O}_{\mathrm{z}}(\mathrm{s})+\mathrm{yCl}_{\mathrm{x}}(\mathrm{g})
$$

When both oxygen and chlorine are present in the corrosive gas, metal-oxygen-chlorine phase stability diagrams (predominance diagrams) helps to predict the stable phase(s) under specific oxygen and chlorine partial pressures. The predominance diagram is based on the minimization of the systems total Gibbs free energy as a function of oxygen and chlorine partial pressures. In the present work, such diagrams calculated for $\mathrm{Fe}, \mathrm{Cr}$ and $\mathrm{Ni}$ using the commercial software package FactSage and are superimposed in Figure 19 [43,44]. It is important to note that for the $\mathrm{Fe}_{-} \mathrm{Cl}_{2}-\mathrm{O}_{2}$ diagram, the line separating solid metal chloride and gas metal chloride phases, only represents the maximum limit for the solid metal chloride because volatile metal chlorides may exit at chlorine partial pressures below this limit [53,54]. According to Figure 19, $\mathrm{Cr}$ and $\mathrm{Fe}$ will require a lower $\mathrm{Cl}_{2}$ partial pressure for chlorination relative to $\mathrm{Ni}$, which requires $\mathrm{p}_{\mathrm{Cl}_{2}}>10^{-11} \mathrm{~atm}$. 


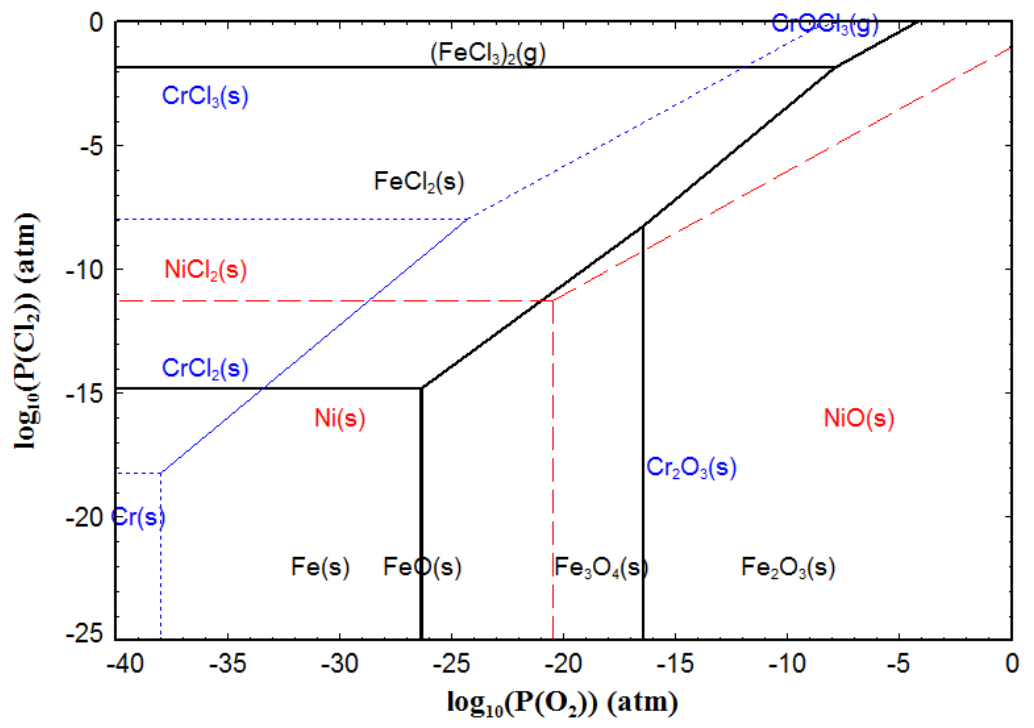

Figure 19. Superimposed predominance diagrams for the $\mathrm{M}-\mathrm{Cl}-\mathrm{O}$ system at $560{ }^{\circ} \mathrm{C}$ showing the stability regions for oxides and chlorides of major alloying elements in the investigated material, $\mathrm{M}$. ( $\mathrm{M}=$ Cr-blue, Fe-black, Ni-red). Calculations were performed with FactSage $[43,44]$ using the Fact PS, FT oxide, FT salt and FT pulp databases.

However, because $\mathrm{CrCl}_{2}$ formation (as well as its transformation to $\mathrm{Cr}_{2} \mathrm{O}_{3}$ ) occurs at relatively lower $\mathrm{O}_{2}$ partial pressures, it is reasonable that only the metal oxides (chlorides) of Fe are observed close to the corrosion product/deposit interface (with high $\mathrm{O}_{2}$ partial pressures) since the $\mathrm{FeCl}_{2} \rightarrow \mathrm{Fe}_{2} \mathrm{O}_{3}$ transformation occurs at higher $\mathrm{O}_{2}$ partial pressures. Results from cross sectional and plan view investigations (cf. Figures 2, 3, 5 and 8) are in good agreement with the thermodynamic calculations as $\mathrm{Fe}_{2} \mathrm{O}_{3}$ was mostly observed in layer 1 below the deposit, whereas the spinel $\left(\mathrm{FeCr}_{2} \mathrm{O}_{4}\right)$ was observed in layer 2. The identification of $\mathrm{Ni}$ in layer 2 of corrosion products (the spinel) is explained by the effect of $\mathrm{Ni}$ in the spinel, where it promotes lower partition of alloying elements [49]. On the other hand, the identification of metallic $\mathrm{Ni}$ in the corrosion products could be because it requires the highest $\mathrm{Cl}_{2}$ partial pressure for chlorination $\left(\mathrm{p}_{\mathrm{Cl}_{2}}>10^{-11} \mathrm{~atm}\right.$, Figure 19).

The selective progression of corrosion attack along the grain boundaries corresponds to the faster diffusion of corrosive species along the grain boundaries. In addition, it has been reported that preferential attack of Cr-carbides [7,55] present at the grain boundaries could favour selective progression of corrosion attack through the grain boundaries. In line with thermodynamics of the chlorination-oxidation process, high volatility of metal chlorides of Fe and faster transport through grain boundaries supports Fe depletion along the attacked grain boundaries (Figure 3 and 7b).

The morphology of $\mathrm{KCl}$ and $\mathrm{Fe}_{2} \mathrm{O}_{3}$ rich corrosion products (on deposit-coated samples exposed to an oxidizing-chlorinating gas mixture) indicate partial melting of $\mathrm{KCl}$ during the exposure and is consistent with the observation that after exposure, the deposit could be removed from the sample surface as a compact layer and not as individual particles (Figure 13b). The transformation of the deposit particles to such molten morphologies is attributed to the ability of $\mathrm{FeCl}_{2}$ to lower the melting temperature of $\mathrm{KCl}\left(772{ }^{\circ} \mathrm{C}\right)$ because the $\mathrm{KCl}-\mathrm{FeCl}_{2}$ system forms a eutectic point at $355^{\circ} \mathrm{C}[43,44]$, 
which is below the temperature at which the present exposures were carried out. Such phase transformation (solid $\rightarrow$ liquid) will exacerbate the corrosiveness of the deposit due to enhanced contact between the sample surface and the corrosive deposit, thus promoting further chlorination of the alloying elements. The corresponding oxidation of dissolved $\mathrm{Fe}$ (i.e. $\mathrm{FeCl}_{2}$ ) in such melts accounts for $\mathrm{Fe}_{2} \mathrm{O}_{3}$ identification in the $\mathrm{KCl}-\mathrm{Fe}_{2} \mathrm{O}_{3}$ mixture.

In general, the corrosion attack observed on deposit-coated samples reflects the interplay between $\mathrm{K}$ and $\mathrm{Cl}$. However it has to be noted that $\mathrm{Cl}$ plays a special role in the corrosion attack, as part of this specie released from reaction (4) possess the tendency of propagating the corrosion attack by reinitiating reaction (3). Thus, $\mathrm{K}$ has one role - breakdown of $\mathrm{Cr}_{2} \mathrm{O}_{3}$, while $\mathrm{Cl}$ has two - formation of a melt on the sample surface and increased generation of $\mathrm{HCl}$, thus, propagating the reaction at the corrosion front. The role of $\mathrm{K}$ is not exclusively necessary to initiate chlorination of the alloy since deposit-free samples exposed to the oxidizing-chlorinating gas mixture also suffered chlorination related corrosion attack (cf. Figure 16).

\section{2}

\section{The influence of $\mathrm{HCl}$ on the corrosion process}

From the severe attack on deposit-free samples after exposure to an oxidizing-chlorinating gas mixture (see Figures 16 and 18), it is obvious that the addition of $\mathrm{HCl}$ to the gas mixture triggered corrosion through a mechanism different from that described for deposit-free samples exposed to an oxidizing gas mixture. Considering a complete dissociation of the original $0.035 \mathrm{vol} \% \mathrm{HCl}$ present in the flue gas, according to the Deacon reaction (2) [51,56], chlorine partial pressure $\left(\mathrm{p}_{\mathrm{Cl}_{2}}\right)$ of $2.91 \times$ $10^{-7}$ atm can be generated at $560{ }^{\circ} \mathrm{C}[43,44]$. Thermodynamically (Figure 19), this can initiate the chlorination of $\mathrm{Cr}$, Fe and Ni under low oxygen partial pressures in accordance with the mechanisms discussed in section 4.1. Indeed, the observed morphology and composition of the corrosion products (Figures 16 and 17) agree reasonably with thermodynamic predictions. As a result of the chlorination reaction, accumulation of Cl-rich features was observed at the corrosion front (Figure 16d). The observed corrosion products are also in good agreement with those from related previous studies [24,25,27,57-59] and the identification of metallic Ni in the EDS maps (Figure 16c) can either be due to its easier incorporation in the spinel [49] or because the actual $\mathrm{Cl}_{2}$ partial pressure at the corrosion front was too low $\left(<10^{-11} \mathrm{~atm}\right)$ for chlorination of $\mathrm{Ni}$.

It is clear from the morphology of the corrosion product, that $\mathrm{HCl}$ alone is not responsible for formation of the heterogeneously distributed, $\mathrm{Fe}_{2} \mathrm{O}_{3}-\mathrm{KCl}$ partly molten layer observed after exposure of deposit-coated samples to an oxidizing-chlorinating gas mixture. However, with the simultaneous presence of both the $\mathrm{KCl}$ deposit and $\mathrm{HCl}$ in the gas mixture (experiment IIa), an increased corrosion attack was observed. Although the elemental composition of the corrosion products remains the same as in the absence of a deposit, the morphology of the corrosion products is obviously different (cf. Figures 11-14 and 16). The enhanced formation of the $\mathrm{KCl}-\mathrm{FeCl}_{2}$ eutectic mixture (Figure 13d) possibly increased the degree of corrosion attack due to enhanced contact between the sample and the partly molten deposit particles. Consequently, a higher $\mathrm{Cl}_{2}$ partial pressure arising from reactions 1 and 2 in combination with the one present in the flue gas facilitated more chlorination of the alloying 
elements (reaction 3). In conformity with this (i.e. increased chlorination of the alloying elements, Fe and $\mathrm{Cr}$ ), deposit particles close to the initial sample surface appeared to have been partly molten (Figure 13b), probably due to formation of a eutectic between the deposit and the volatized $\mathrm{FeCl}_{2}$ (from reactions 3). A manifestation of increased volatilization of metal chlorides resulting from reactions 3 and 4 is the porous, bubble-like and heterogeneous morphology of the $\mathrm{Fe}_{2} \mathrm{O}_{3}-\mathrm{KCl}$ layer 1 as observed from plan-view investigations (Figure 13c). While such layers may have been initiated in the oxidizing gas mixture (experiment Ia) through the process involving $\mathrm{K}_{2} \mathrm{CrO}_{4}$ formation (reaction 1), the bubble-like and heterogeneous nature of the layer in experiment IIa clearly indicates that $\mathrm{HCl}$ addition to the gas mixture had a significant effect on volatilization of metal chlorides formed during the corrosion process. Increased chlorination and volatilization leading to selective removal of the alloying elements ( $\mathrm{Fe}$ and $\mathrm{Cr}$ ) is responsible for the formation of a Ni-rich phase (in layer 3) as identified by XRD.

Summary and conslusions

Systematic investigations of the high temperature corrosion of an austenitic superheater material (TP 347H FG) at $560{ }^{\circ} \mathrm{C}$ under conditions relevant for biomass firing in thermal power plants show that both deposit $(\mathrm{KCl})$ particles and the corrosive flue gas composition affect the corrosion process. Based on the results from this study, the following conclusions can be deduced:

1. The alloy suffers corrosion attack under all the conditions investigated.

2. More severe corrosion attack occurs on KCl-deposit coated samples compared to the deposit-free samples when exposed to the same gaseous mixture.

3. Corrosion attack on deposit-free samples exposed to an oxidizing gas mixture follows the conventional oxidation mechanism leading to a double-layered oxide. No grain boundary attack occurs under this condition. However, the presence of a $\mathrm{KCl}$ deposit significantly changes the corrosion attack due to the influence of both $\mathrm{K}$ and $\mathrm{Cl}$. Selective attack of $\mathrm{Cr}$ along the grain boundaries occurs after such exposure.

4. $\mathrm{HCl}$ in the flue gas significantly enhances the chlorination of alloying elements leading to formation of volatile metal chlorides. In the absence of $\mathrm{KCl}$, this effect results in a typical Clinduced type of corrosion attack (chlorination) progressing through the grain boundaries.

5. When $\mathrm{KCl}$ is present on the sample, addition of $\mathrm{HCl}$ to the gas mixture increases the formation of a corrosive $\mathrm{FeCl}_{\mathrm{x}}-\mathrm{KCl}$ eutectic, and hence, increases the selective attack of the thermodynamically favoured species ( $\mathrm{Fe}$ and $\mathrm{Cr}$ ). This leads to formation of a Ni-rich phase close to the corrosion front. The corrosion products resulting from this attack are highly porous and heterogeneous due to severe volatilization of the formed metal chlorides.

\section{Acknowledgements}

This work is part of the Danish Strategic Research Centre, Power Generation from Renewable Energy (GREEN). The authors acknowledge funding from the Danish council for Strategic Research. 


\section{References}

[1] F.J. Frandsen, Utilizing biomass and waste for power production-a decade of contributing to the understanding, interpretation and analysis of deposits and corrosion products, Fuel. 84 (2005) 1277-1294.

[2] M. Montgomery, S.A. Jensen, U. Borg, O. Biede, T. Vilhelmsen, Experiences with high temperature corrosion at straw-firing power plants in Denmark, Mater. Corros. 62 (2011) 593-605.

[3] K.A. Christensen, H. Livbjerg, A Field Study of Submicron Particles from the Combustion of Straw, Aerosol Sci. Technol. 25 (1996) 185-199.

[4] P.A. Tchoffor, K.O. Davidsson, H. Thunman, Transformation and Release of Potassium, Chlorine, and Sulfur from Wheat Straw under Conditions Relevant to Dual Fluidized Bed Gasification, Energy \& Fuels. 27 (2013) 7510-7520.

[5] S. V. Vassilev, D. Baxter, L.K. Andersen, C.G. Vassileva, T.J. Morgan, An overview of the organic and inorganic phase composition of biomass, Fuel. 94 (2012) 1-33.

[6] J.M. Johansen, J.G. Jakobsen, F.J. Frandsen, P. Glarborg, Release of K, Cl, and S during Pyrolysis and Combustion of High-Chlorine Biomass, Energy \& Fuels. 25 (2011) 49614971.

[7] M. Montgomery, A. Karlsson, O.H. Larsen, Field test corrosion experiments in Denmark with biomass fuels. Part 1: Straw-firing, Mater. Corros. 53 (2002) 121-131.

[8] P. Viklund, A. Hjörnhede, P. Henderson, A. Stålenheim, R. Pettersson, Corrosion of superheater materials in a waste-to-energy plant, Fuel Process. Technol. 105 (2013) 106-112.

[9] C. Liu, J.A. Little, P.J. Henderson, P. Ljung, Corrosion of TP347H FG stainless steel in a biomass fired PF utility boiler, J. Mater. Sci. 36 (2001) 1015-1026.

[10] M. Montgomery, A. Karlsson, In-situ corrosion investigation at Masnedø CHP plant - a straw-fired power plant, Mater. Corros. 50 (1999) 579-584.

[11] H.P. Nielsen, Deposition and High-temperature Corrosion in Biomass-Fired Boilers, PhD Thesis, Technical University of Denmark, 1998.

[12] H.P. Michelsen, F.J. Frandsen, K. Dam-Johansen, O.H. Larsen, Deposition and high temperature corrosion in a 10 MW straw fired boiler, Fuel Process. Technol. 54 (1998) 95108.

[13] M. Montgomery, O.H. Larsen, Field test corrosion experiments in Denmark with biomass fuels. Part 2: Co-firing of straw and coal, Mater. Corros. 53 (2002) 185-194.

[14] H.P. Nielsen, F.J. Frandsen, K. Dam-Johansen, Lab-Scale Investigations of HighTemperature Corrosion Phenomena in Straw-Fired Boilers, Energy \& Fuels. 13 (1999) 1114 1121.

[15] S.C. Van Lith, F.J. Frandsen, M. Montgomery, T. Vilhelmsen, S.A. Jensen, Lab-scale Investigation of Deposit-induced Chlorine Corrosion of Superheater Materials under 
Simulated Biomass-firing Conditions. Part 1: Exposure at $560{ }^{\circ} \mathrm{C}$, Energy \& Fuels. 59 (2009) 3457-3468.

[16] T. Jonsson, N. Folkeson, J.-E. Svensson, L.-G. Johansson, M. Halvarsson, An ESEM in situ investigation of initial stages of the $\mathrm{KCl}$ induced high temperature corrosion of a $\mathrm{Fe}-2.25 \mathrm{Cr}-$ 1Mo steel at $400^{\circ} \mathrm{C}$, Corros. Sci. 53 (2011) 2233-2246.

[17] J. Lehmusto, D. Lindberg, P. Yrjas, B.-J. Skrifvars, M. Hupa, Thermogravimetric studies of high temperature reactions between potassium salts and chromium, Corros. Sci. 59 (2012) 55-62.

[18] C. Pettersson, J. Pettersson, H. Asteman, J.-E. Svensson, L.-G. Johansson, KCl-induced high temperature corrosion of the austenitic Fe-Cr-Ni alloys 304L and Sanicro 28 at $600^{\circ} \mathrm{C}$, Corros. Sci. 48 (2006) 1368-1378.

[19] M.. Uusitalo, P.M.. Vuoristo, T.. Mäntylä, High temperature corrosion of coatings and boiler steels below chlorine-containing salt deposits, Corros. Sci. 46 (2004) 1311-1331.

[20] Y.S. Li, M. Spiegel, S. Shimada, Corrosion behaviour of various model alloys with NaClKCl coating, Mater. Chem. Phys. 93 (2005) 217-223.

[21] S. Enestam, D. Bankiewicz, J. Tuiremo, K. Mäkelä, M. Hupa, Are NaCl and KCl equally corrosive on superheater materials of steam boilers?, Fuel. 104 (2013) 294-306.

[22] S. Karlsson, J. Pettersson, L.-G. Johansson, J.-E. Svensson, Alkali Induced High Temperature Corrosion of Stainless Steel: The Influence of $\mathrm{NaCl}, \mathrm{KCl}$ and $\mathrm{CaCl}$, Oxid. Met. 78 (2012) 83-102.

[23] J. Lehmusto, B.-J. Skrifvars, P. Yrjas, M. Hupa, High temperature oxidation of metallic chromium exposed to eight different metal chlorides, Corros. Sci. 53 (2011) 3315-3323.

[24] M.K. Hossain, The influence of $\mathrm{HCl}$ gas in enhancing corrosion rates in Ni-Cr-base alloys and the implications for coal-fired gas turbines, Corros. Sci. 21 (1981) 843-861.

[25] H. Asteman, M. Spiegel, Investigation of the $\mathrm{HCl}$ (g) attack on pre-oxidized pure Fe, Cr, Ni and commercial 304 steel at $400^{\circ} \mathrm{C}$, Corros. Sci. 49 (2007) 3626-3637.

[26] T. Jonsson, N. Folkeson, M. Halvarsson, J.-E. Svensson, L.-G. Johansson, Microstructural Investigation of the HCl-Induced Corrosion of the Austenitic Alloy 310S (52Fe26Cr19Ni) at $500{ }^{\circ} \mathrm{C}$, Oxid. Met. 81 (2014) 575-596.

[27] P. Viklund, R. Pettersson, HCl-Induced High Temperature Corrosion of Stainless Steels in Thermal Cycling Conditions and the Effect of Preoxidation, Oxid. Met. 76 (2010) 111-126.

[28] K. Salmonoja, M. Hupa, R. Backman, Laboratory studies on the influence of gaseous $\mathrm{HCl}$ on fireside corrosion of superheaters, J. Inst. Energy. 72 (1999) 127-133.

[29] N. Folkeson, L.-G. Johansson, J.-E. Svensson, Initial Stages of the HCl-Induced HighTemperature Corrosion of Alloy 310, J. Electrochem. Soc. 154 (2007) C515.

[30] S.C. Cha, High temperature corrosion of superheater materials below deposited biomass ashes in biomass combusting atmospheres, Corros. Eng. Sci. Technol. 42 (2007) 50-60. 
[31] H. Asteman, J.-E. Svensson, L.-G. Johansson, Oxidation of 310 steel in H2O/O2 mixtures at $600{ }^{\circ} \mathrm{C}$ : the effect of water-vapour-enhanced chromium evaporation, Corros. Sci. 44 (2002) 2635-2649.

[32] N. Israelsson, K. Hellström, J.-E. Svensson, L.-G. Johansson, KCl-Induced Corrosion of the FeCrAl Alloy Kanthal ${ }^{\circledR}$ AF at $600{ }^{\circ} \mathrm{C}$ and the Effect of H2O, Oxid. Met. 83 (2015) 1-27.

[33] J. Pettersson, J.-E. Svensson, L.-G. Johansson, KCl-Induced Corrosion of a 304-type Austenitic Stainless Steel in $\mathrm{O} 2$ and in $\mathrm{O} 2$ + H2O Environment: The Influence of Temperature, Oxid. Met. 72 (2009) 159-177.

[34] T. Jonsson, B. Pujilaksono, S. Hallström, J. Ågren, J.-E. Svensson, L.-G. Johansson, M. Halvarsson, An ESEM in situ investigation of the influence of $\mathrm{H} 2 \mathrm{O}$ on iron oxidation at $500^{\circ} \mathrm{C}$, Corros. Sci. 51 (2009) 1914-1924.

[35] S. Karlsson, J. Pettersson, J.E. Svensson, L.G. Johansson, KCl-Induced High Temperature Corrosion of the Austenitic Stainless Steel 304L - The Influence of SO2, Mater. Sci. Forum. 696 (2011) 224-229.

[36] K. Hellström, J. Hall, P. Malmberg, Y. Cao, M. Norell, J.-E. Svensson, Mitigation of Fireside Corrosion in Power Plants: The Combined Effect of Sulfur Dioxide and Potassium Chloride on the Corrosion of a FeCrAl Alloy, Energy \& Fuels. 28 (2014) 6116-6129.

[37] M. Paneru, G. Stein-Brzozowska, J. Maier, G. Scheffknecht, Corrosion Mechanism of Alloy 310 Austenitic Steel beneath $\mathrm{NaCl}$ Deposit under Varying SO2 Concentrations in an Oxyfuel Combustion Atmosphere, Energy \& Fuels. 27 (2013) 5699-5705.

[38] S. Karlsson, T. Jonsson, J. Hall, J.-E. Svensson, J. Liske, Mitigation of Fireside Corrosion of Stainless Steel in Power Plants: A Laboratory Study of the Influences of SO2 and $\mathrm{KCl}$ on Initial Stages of Corrosion, Energy \& Fuels. 28 (2014) 3102-3109.

[39] J. Hansen, F.J. Frandsen, P.G. Kristensen, C.E. Nielsen, K. Dam-Johansen, Gas analyses and alkali measurements at MKS1, CHEC Report 9620, Lyngby, 1996.

[40] S.C. Okoro, S. Kiamehr, M. Montgomery, F.J. Frandsen, K. Pantleon, Effect of flue gas composition on deposit induced high temperature corrosion under laboratory conditions mimicking biomass firing. Part II: Exposures in SO 2 containing atmospheres, Mater. Corros. 68 (2017) 515-528.

[41] S. Kiamehr, K.V. Dahl, M. Montgomery, M.A.J. Somers, KCl-induced high temperature corrosion of selected commercial alloys. Part I: chromia-formers, Mater. Corros. 66 (2015) 1414-1429.

[42] S.C. Okoro, M. Montgomery, F.J. Frandsen, K. Pantleon, High Temperature Corrosion under Laboratory Conditions Simulating Biomass-Firing: A Comprehensive Characterization of Corrosion Products, Energy \& Fuels. 28 (2014) 6447-6458.

[43] C.W. Bale, E. Bélisle, P. Chartrand, S.A. Decterov, G. Eriksson, K. Hack, I.-H. Jung, Y.-B. Kang, J. Melançon, A.D. Pelton, C. Robelin, S. Petersen, FactSage thermochemical software and databases - recent developments, Calphad. 33 (2009) 295-311.

[44] What's New in FactSage 7.0, (2015). http://www.crct.polymtl.ca/fact/facthelp/FS70New.htm 
(accessed June 2, 2016).

[45] R.P. Reed, R.E. Schramm, Lattice Parameters of Martensite and Austenite in Fe-Ni Alloys, J. Appl. Phys. 40 (1969) 3453.

[46] R.E. Schramm, R.P. Reed, Stacking fault energies of fcc fe-Ni alloys by x-ray diffraction line profile analysis, Metall. Trans. A. 7 (1976) 359-363.

[47] N. Birks, G.H. Meier, F.S. Pettit, Introduction to the High Temperature Oxidation of Metals, Second Edi, Cambridge University Press, New York, 2009.

[48] D.J. Young, Effects of Water Vapour on Oxidation, in: Corros. Ser., Elsevier, 2008: pp. 455495.

[49] A.N. Hansson, K. Pantleon, F.B. Grumsen, M.A.J. Somers, Microstructure Evolution During Steam Oxidation of a Nb Stabilized Austenitic Stainless Steel, Oxid. Met. 73 (2009) 289309.

[50] R.A. Antunes, M.C.L. de Oliveira, Corrosion in biomass combustion: A materials selection analysis and its interaction with corrosion mechanisms and mitigation strategies, Corros. Sci. 76 (2013) 6-26.

[51] A. Zahs, M. Spiegel, H. Grabke, The influence of alloying elements on the chlorine-induced high temperature corrosion of Fe-Cr alloys in oxidizing atmospheres, Mater. Corros. 50 (1999) 561-578.

[52] N. Folkeson, T. Jonsson, M. Halvarsson, L.-G. Johansson, J.-E. Svensson, The influence of small amounts of $\mathrm{KCl}(\mathrm{s})$ on the high temperature corrosion of a Fe-2.25Cr-1Mo steel at 400 and $500^{\circ} \mathrm{C}$, Mater. Corros. 62 (2011) 606-615.

[53] H. Latreche, S. Doublet, M. Schütze, Development of Corrosion Assessment Diagrams for High Temperature Chlorine Corrosion. Part I: State of the Art and Development of the Basis for a New Extended Approach, Oxid. Met. 72 (2009) 1-30.

[54] H. Latreche, S. Doublet, M. Schütze, Development of Corrosion Assessment Diagrams for High Temperature Chlorine Corrosion Part II: Development of “Dynamic” Quasi-stability Diagrams, Oxid. Met. 72 (2009) 31-65.

[55] H.P. Nielsen, F.J. Frandsen, K. Dam-Johansen, L.L. Baxter, The implications of chlorineassociated corrosion on the operation of biomass-fired boilers, Prog. Energy Combust. Sci. 26 (2000) 283-298.

[56] A. Ruh, M. Spiegel, Influence of gas phase composition on the kinetics of chloride melt induced corrosion of pure iron (EU-project OPTICORR), Mater. Corros. 57 (2006) 237-243.

[57] K. Nakagawa, Y. Matunaga, Effect of $\mathrm{HCl}$ on the corrosion of waterwall tubes in a wate incineration plant, Mater. High Temp. 14 (2005) 245-250.

[58] P. Mayer, A. V. Manolescu, Influence of Hydrogen Chloride on Corrosion of Boiler Steels in Synthetic Flue Gas, Corrosion. 36 (1980) 369-373.

[59] Y. Ihara, H. Ohgame, K. Sakiyama, The Corrosion Behaviour of Iron in Hydrogen Chloride 
Gas and Gas Mixtures of Hydrogen Chloride and Oxygen at High Temperatures, Corros. Sci. 21 (1981) 805-817. 